\title{
QUALITY OF EXTENSION TRAINING IN EGYPT BASED ON INTERNATIONAL STANDARD ISO 10015: CASE STUDY OF THE TRAINING DEPARTMENTS DIRECTORATES AGRICULTURE ON THE REPUBLIC.
}

\section{Sarhan, A.M.M. and Rabab W. Ghozy}

Agricultural Economic and Extension Dept., Faculty of Agric., South Valley University

Agricultural extension and rural dept., Faculty of Agriculture, Mansoura University

\section{جودة التدريب الإرشادي في مصر في اطار المواصفة الدولية الأيزو ه 1 . . 1 : دراسـة حالـة على اقسـام التدريب

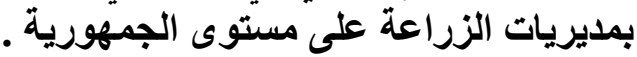

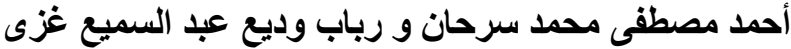

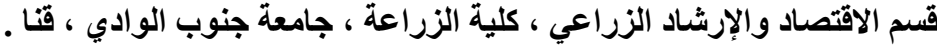

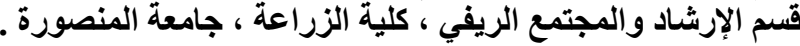 الملخص}

استهدف هذا البحث بصفة رئيسية التعرف على و اقع تطبيق المواصفة الدولية للتدريب (ISO10015) في أقسام التدريب بمديريات

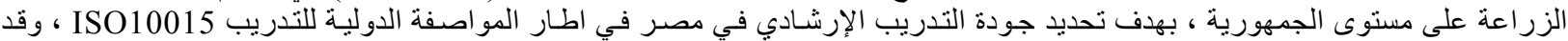

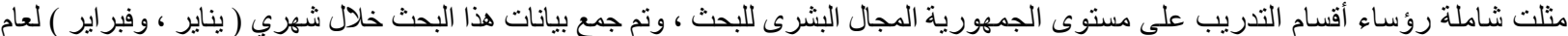

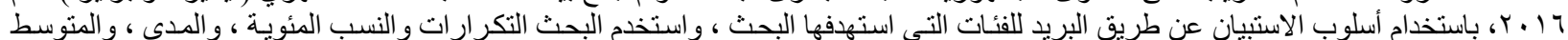

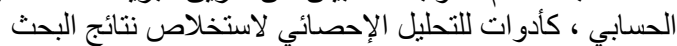

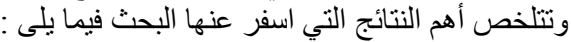

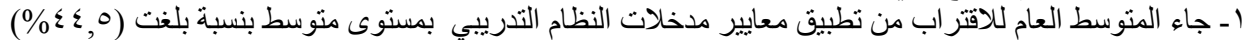

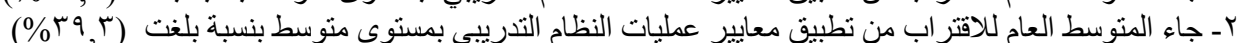

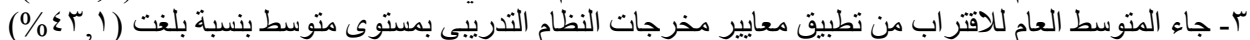

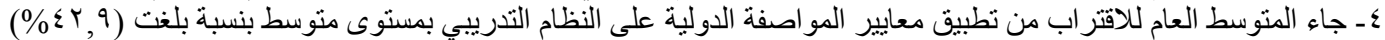

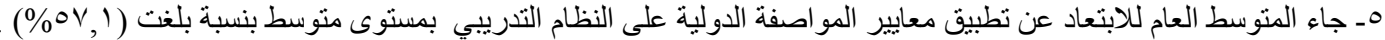

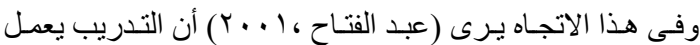

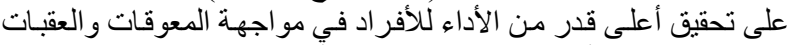

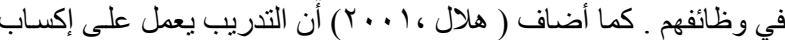

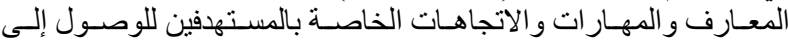
أفضل صور للأداء

ويتوقف نجـاح الجهاز الإرشـادي الزر اعسي في تحقيـق أهدافـهـ

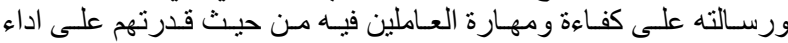

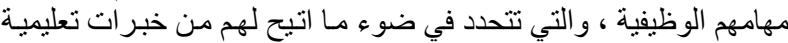

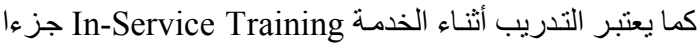

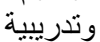

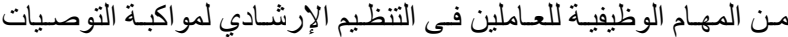

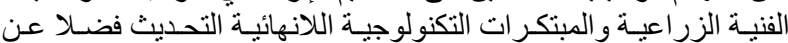

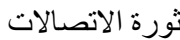

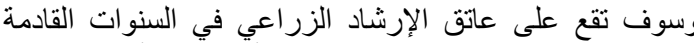

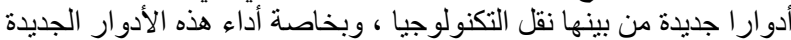

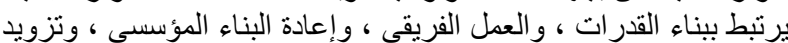

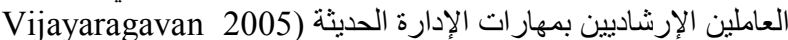

هذا فضلا عن أن بعض التوجهات الرئيسية لاستر اتيجية التنميـة (et al.,

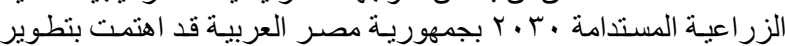

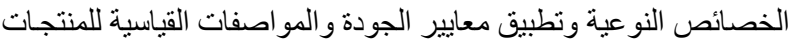

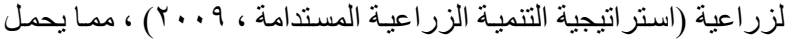

الإرشاد الزر اعي مسئولية جديدة نحو شكل الخدمة الزية الإرشادية المقدمة

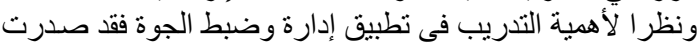

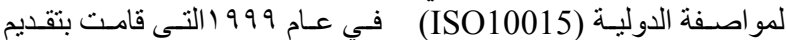

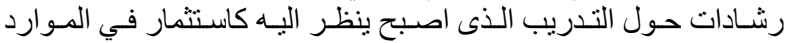

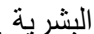

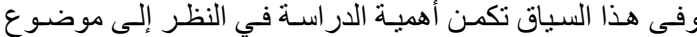

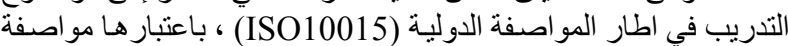

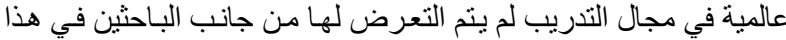

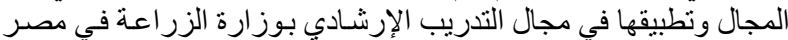

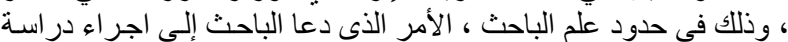

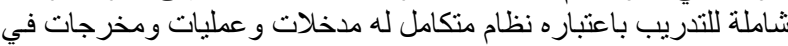

\section{المقدمة و المشكلة البحثية}

يزداد العالم يوما بعد بوم تشابكا وانفتاحا ، و أصبح التنافس بين

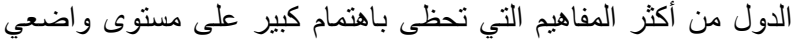

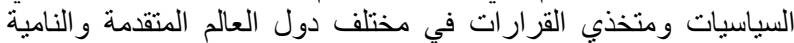

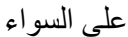

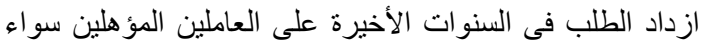
في القطاع العام أو الخاص نتيجة للتغير ات الدات الدولية في سوق العمل وزيادة العادئ

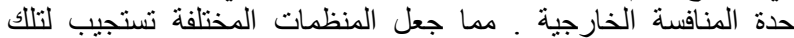
التغير ات لتصبح أكثر كفاءة (Gould-williams,2003).

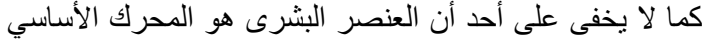

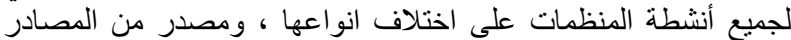

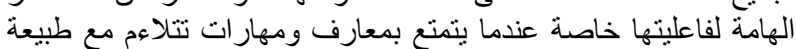

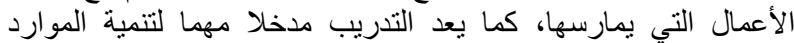

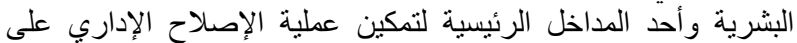

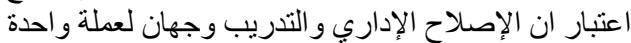

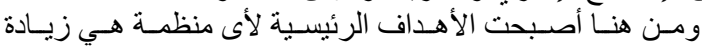

مستوى الإنتاجية حيث يتمثل دور العنصر البشرى في زيادة لإني تلك الإنتاجية

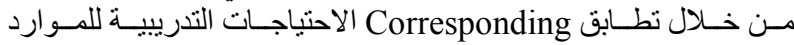

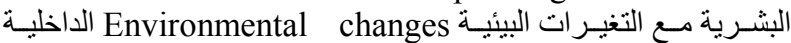

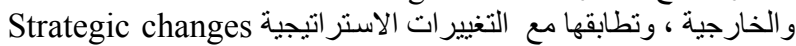

(Asgari \& maddahi, 2013)

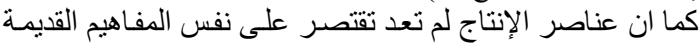

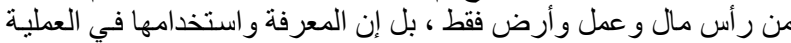

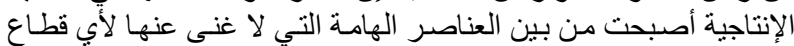

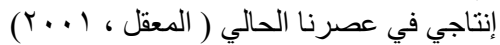

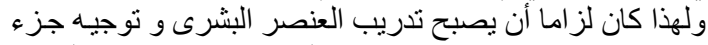

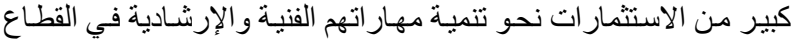

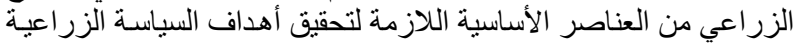

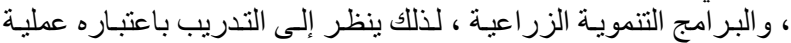

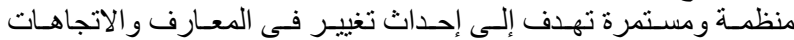

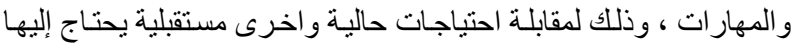

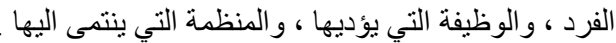


(ISO10015) هي بمثابة حلا للحصول على الجودة ، وذلك لأن معايير

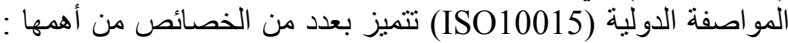

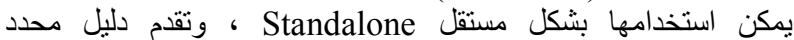

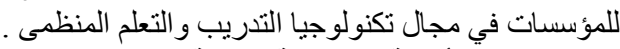
ثانيا : مفهوم وأهمية المواصفة الدولية الدولية (ISO10015) .

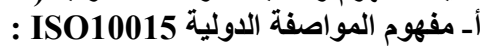

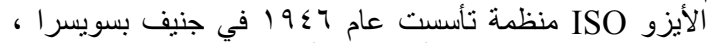

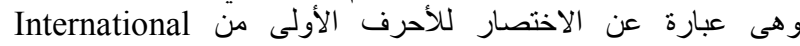

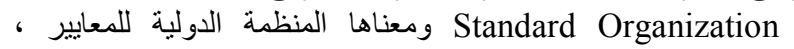

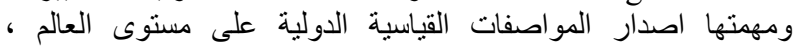

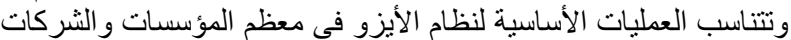

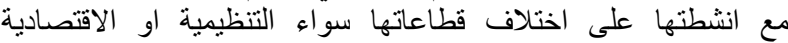

. (Russell \& Taylor, 1995)

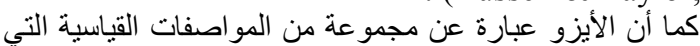

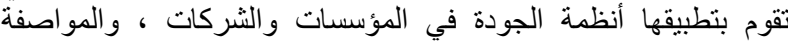
الدولية (ISO10015) واحدة من المعايير الهائلة التي بنيت بواستة

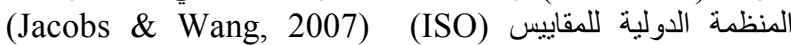
. International Standard Organization حيث اسهمت المنظمة الدولية للمعايير فى وضع معايير لضمان

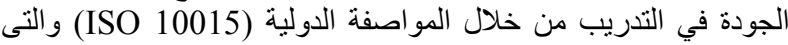

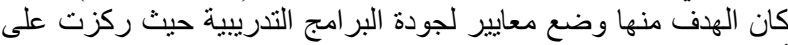

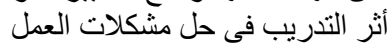

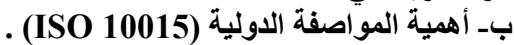
ترجع أهمية المواصفة الدولية (10015 الدولة (ISO) إلى أنها مو اصفة

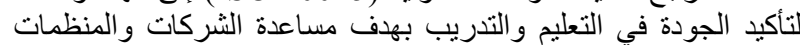

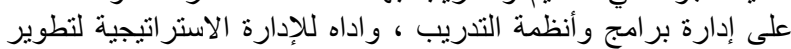

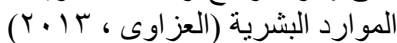

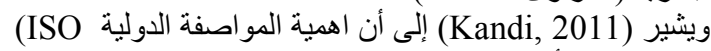

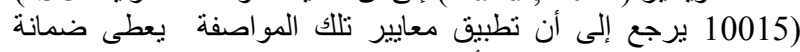

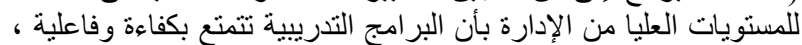

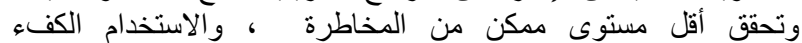
Efficiently utilized وحدد (Saner\& Yiu, 2013) الملامح الأساسية لأهمية للفية

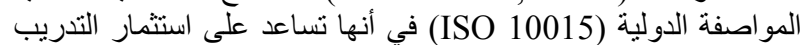

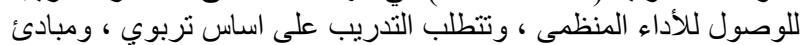

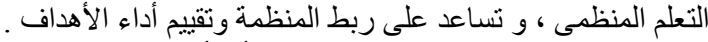

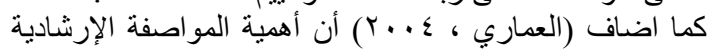

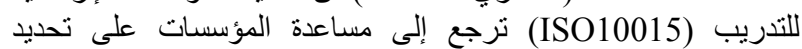

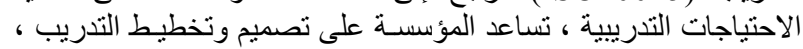

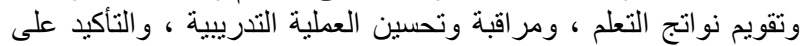

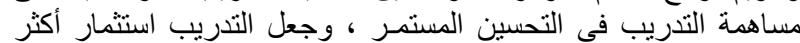

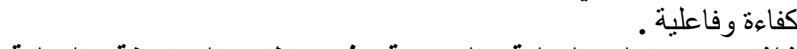

ثالثا : مراحل العملية التدريبية في إطار المواصفة الدولية (ISO10015)

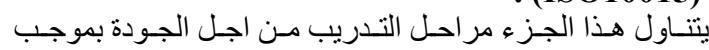

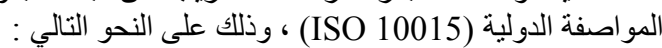

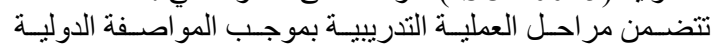

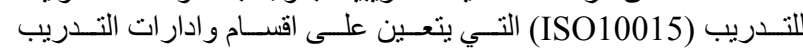

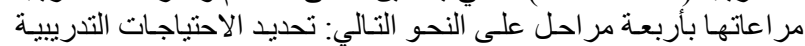
و Defining Training Needs و التدريبTraining Plan Specification، وتنفيذ اشتر اطات التدريب Evaluating و وتقييم مخرجات التدريب ونتئ Providing for Training Training Outcomes

ونستعرض مر احل عملية التدريب من أجل الجودة كما في الثكل

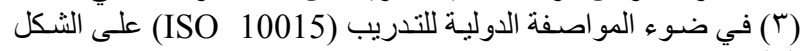

اطلار المواصفة الدولية (ISO10015) حتى يتمكن القائمين و المسئولين

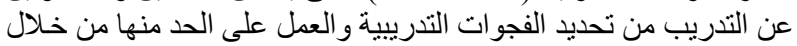

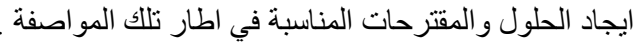

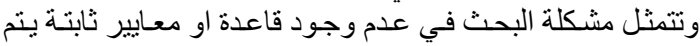

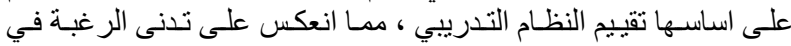

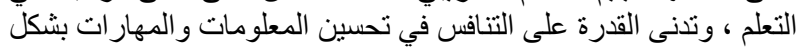
افضل ، و اكساب السلوك و والاتجاهات الإيجابية للفئات المستهدفة بالئات بالتدريب

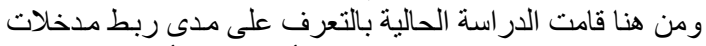

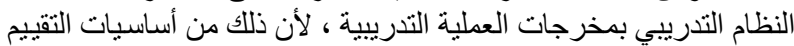

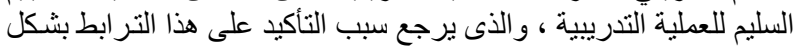

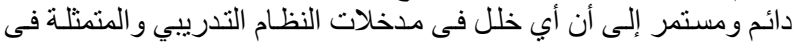

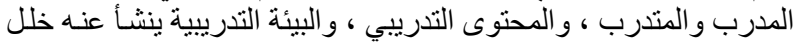

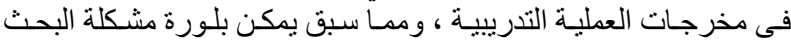

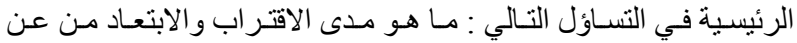

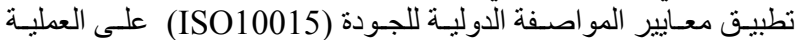

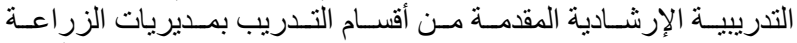

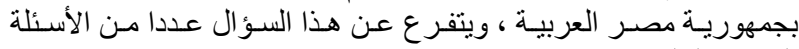

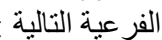

ا ـ ما هو و اقع الاقتر اب او الابتعاد عن تطبيق معايير المواصفة الدولية

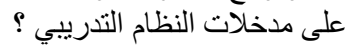

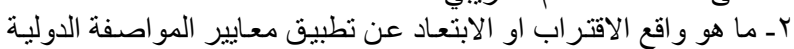

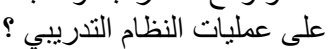

rـ ما هو واقع الاقتراب او الابتعـاد عن تطبيق معابيير المواصفة الدولية

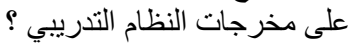

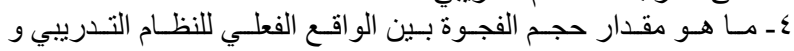

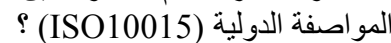

هـ كيف يمكن الاستفادة مـن معـايير المو اصـفة الدوليـة (ISO10015)

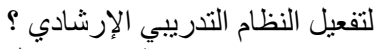

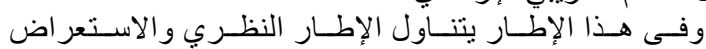

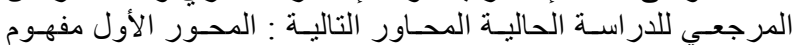

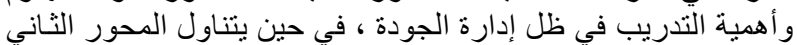

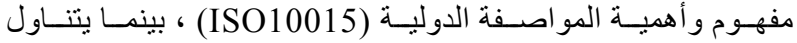

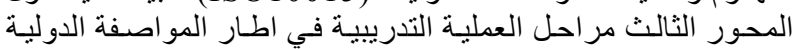

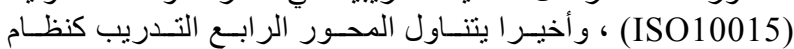

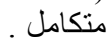

أولا : مفهوم وأهمية التدريب في ظل إدارة الجودة .

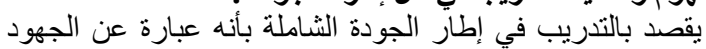

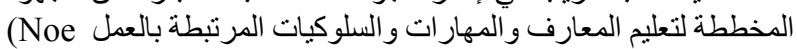
et al, 1995, p.56)

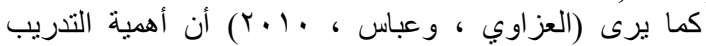

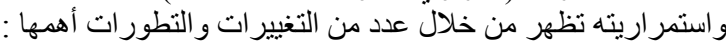

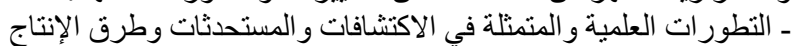

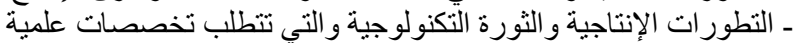

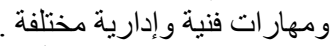

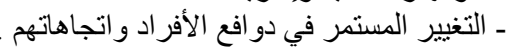

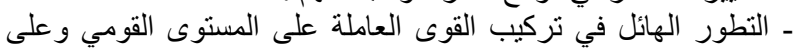

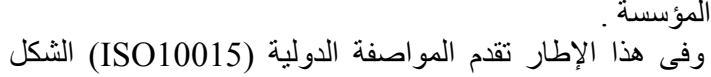

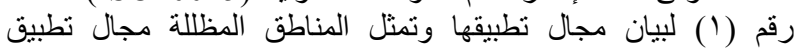

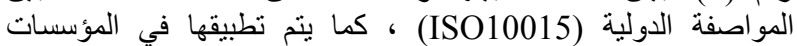
والمنظمات التي تقام التدريب للعاملين فيها كأسلوب لتحسين وتطين وتطوير

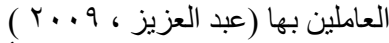
والفاعلية التدريبية يجب النب أن تحدد في ضوء تدريب الموظفين

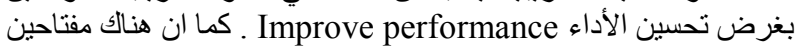

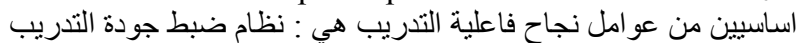
، ونظام تصميم الخطط التدريبية ـ وفى هذا الصدد فإن المو اصفة الدولية 


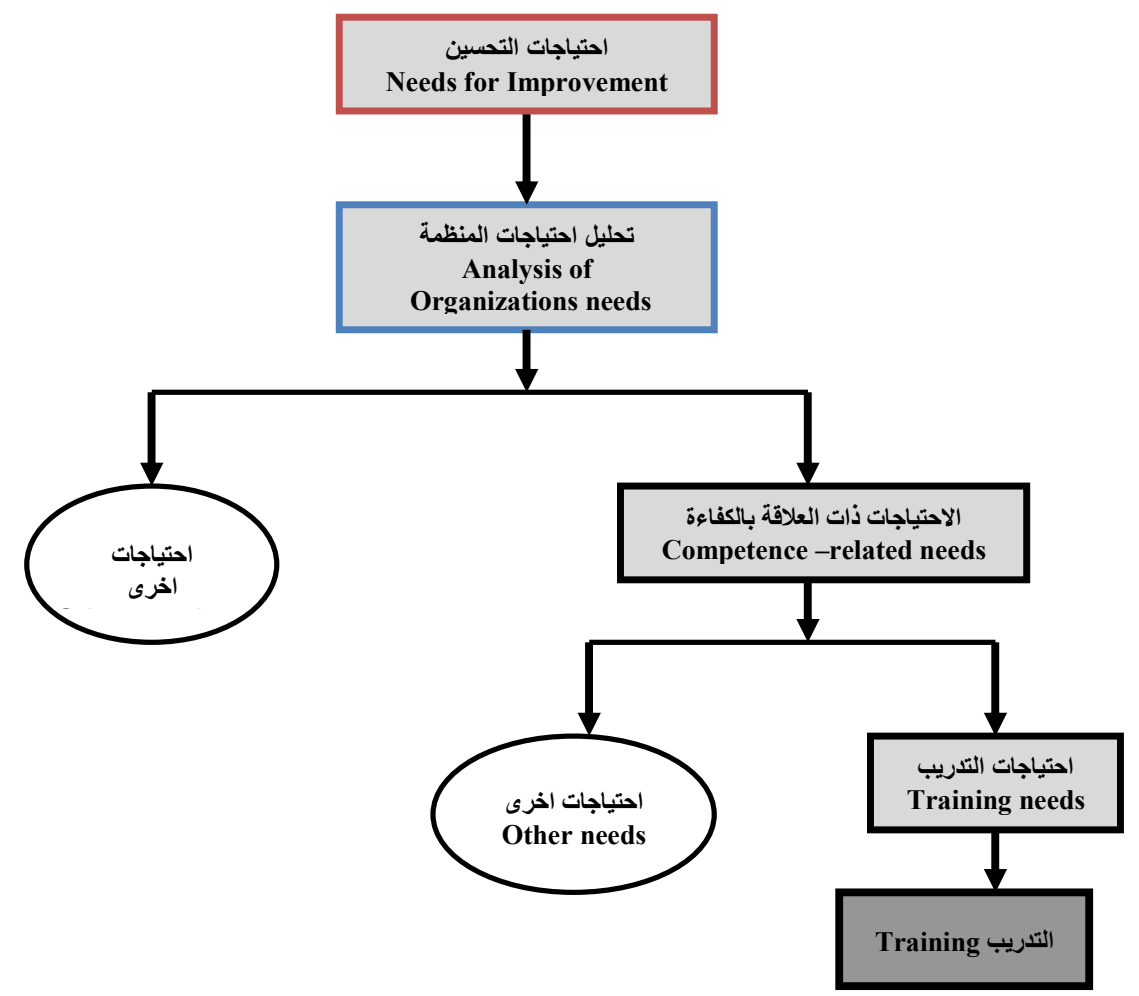

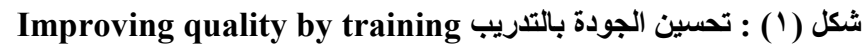

المصدر : (ISO 10015,1999)

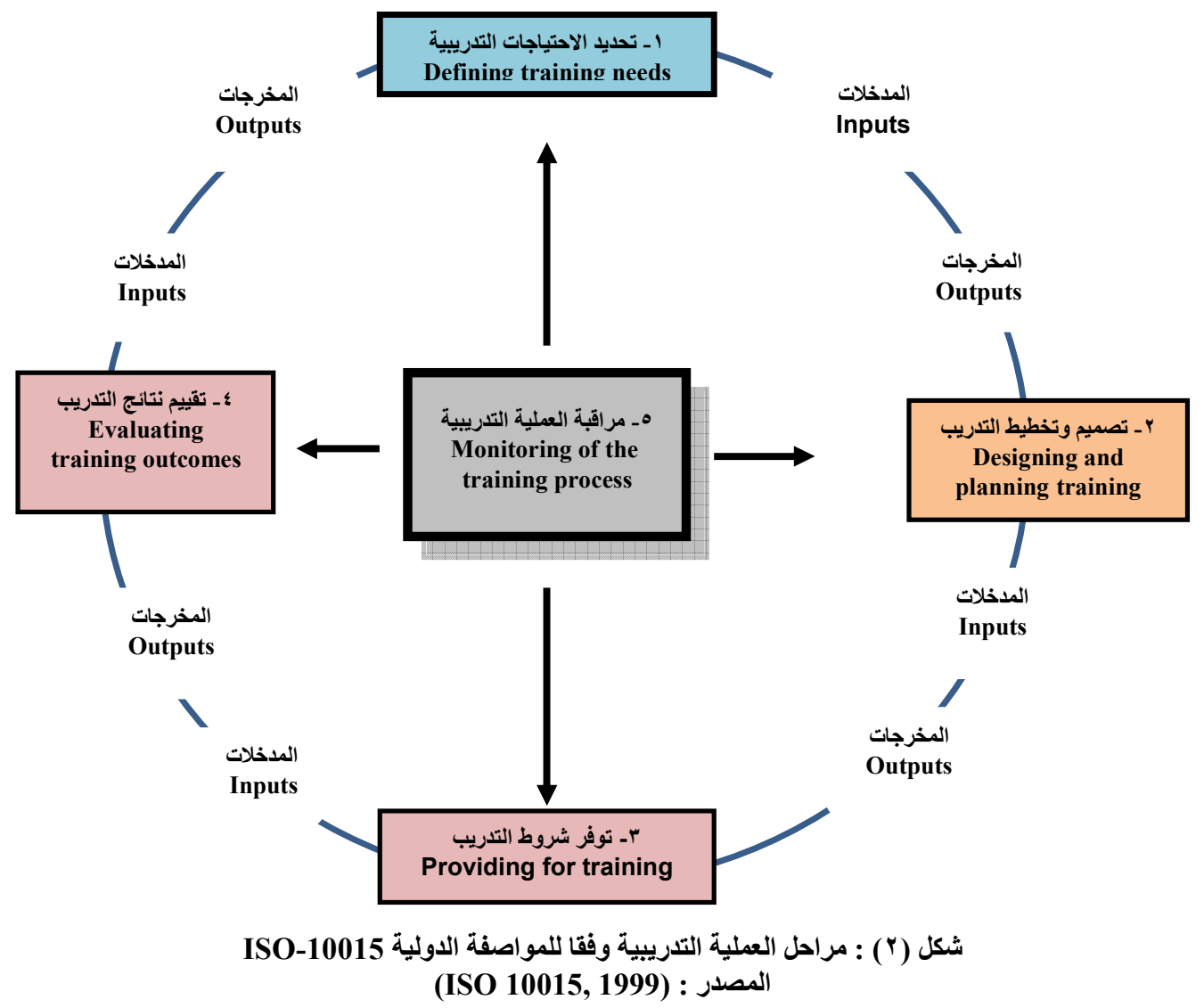




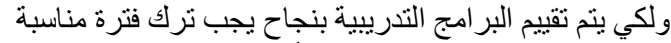

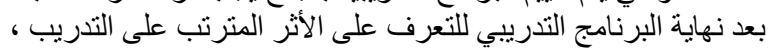

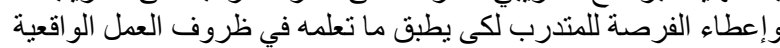
، والتعرف على التغير ات فى السلوك كنتيجة للتدريب (Sanderson, ) 1992

Monitoring : المرحلة الخامسة : مراقبة وتحسين العملية التدريبية and improving the training process

وفى هذا الإطار يتم اعتبار مر اقبة وتحسين العملية التدريبية

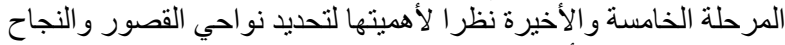

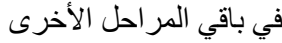
وحددث المواصفة الدولية (ISO 10015) أن الغرض الإن الرئيسي

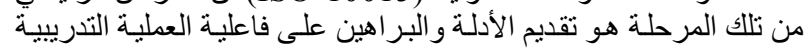

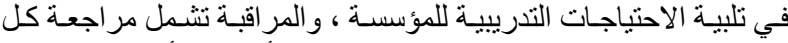

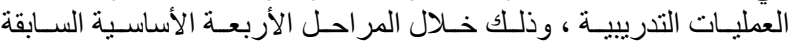

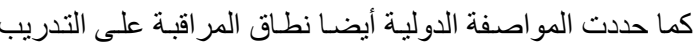

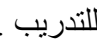

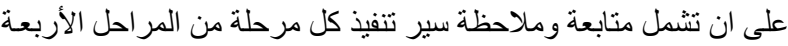

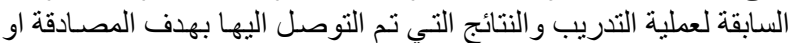

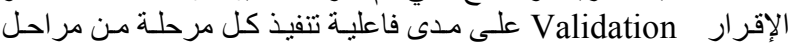

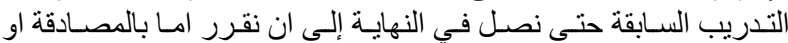

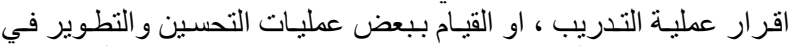

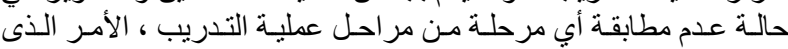

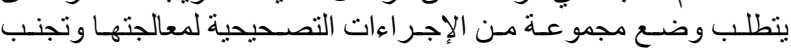

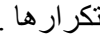
رابعا : التدريب كنظام متكامل.

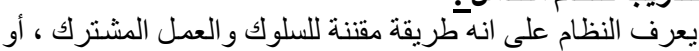

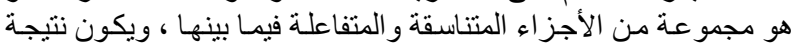
هذا التفاعل مخرجات محددة يمكن قياسها

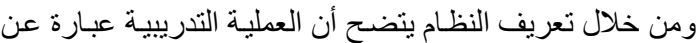

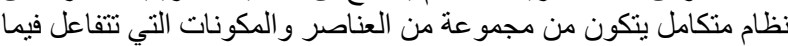

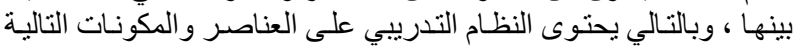

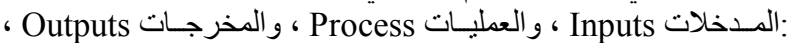

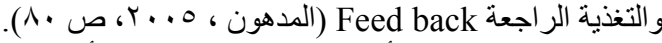

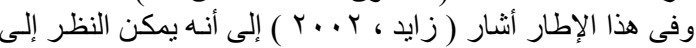

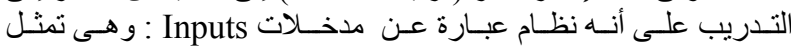
الاحتياجات التدريبة Training needs ، و عمليات أنسات

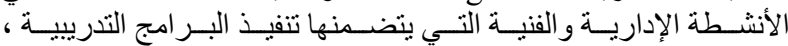

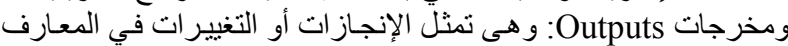

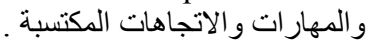

وفى اطار المواصفة الدولية للتدريب (ISO1015) فإن العملية

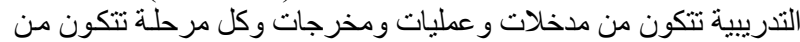

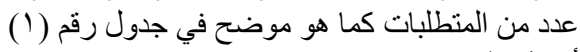

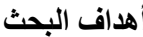

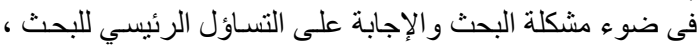
والأسئلة الفر عية التابعة له ، ، تم صياغة الأهد الأهداف البحثية التالية:

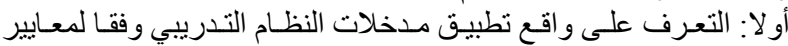
المو اصفة الدولية للتدريب (ISO 10015)

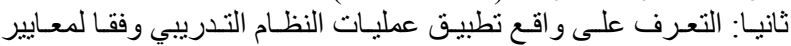
المو اصفة الدولية للتدريب (ISO 10015)

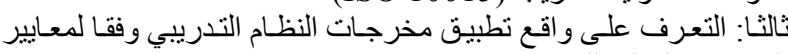
المو اصفة الدولية للتدريب (ISO 10015) رابعـا: التعـرف على مقدار الفجـوة بـين الو اقع الفعلـي للنظـام التـدريبي ومعايير المواصفة الدولية للندريب (ISO 10015)
Defining training المرحلة الأولى : تحديد الاحتياجـات التدريبية needs

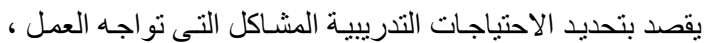

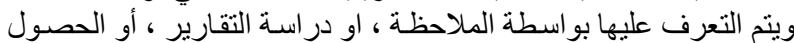

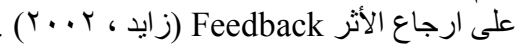

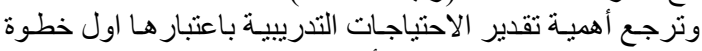

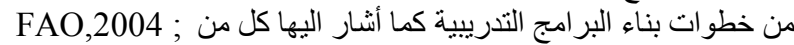

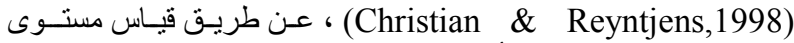

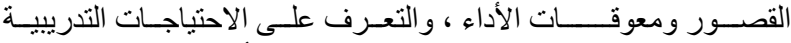

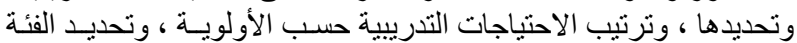

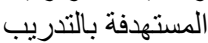

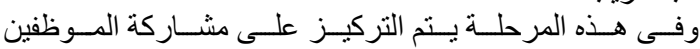
Involvement of personnel

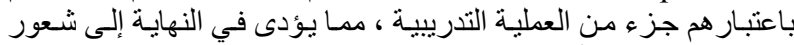

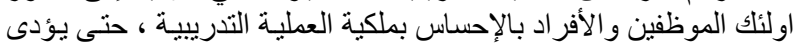

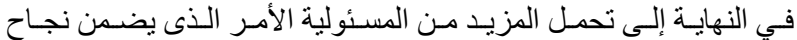

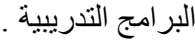

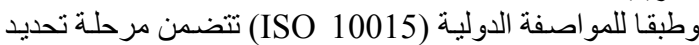

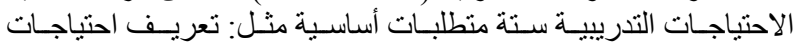
المؤسسة Defining of the organization needs ، وتعريف وتحليل

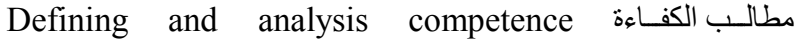
، Competence Reviewing و ومراجعـة الكفــاءة requirements وتحديد فجوات الكفاءة : Defining of competence gaps ، وتحديد

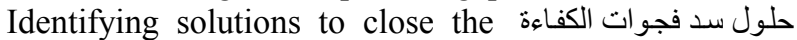
competence gaps ، وتعريـف مواصــفات الاحتياجــات التدريبـة . Defining of the specification for training needs Designing and المرحلة الثانية : تصميم وتخطيط التدريب planning of training بقصد بعملية تصميم وتخطيط البرنامج التدريبي بأنها العملية التي

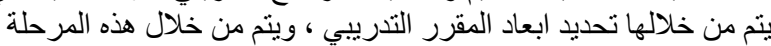

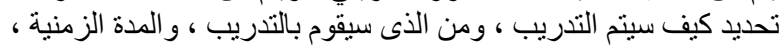

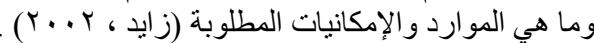

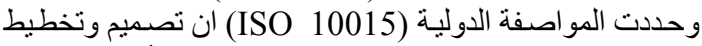

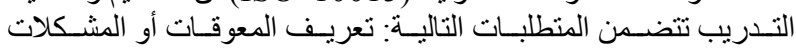
، Defining the constraints الاختيار Training methods and criteria for selection

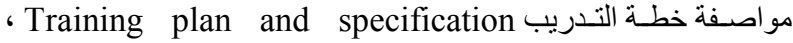

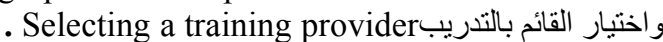

Providing for : المرحلة الثالثة : توفير اشتراطات (تنفيذ) التدريب

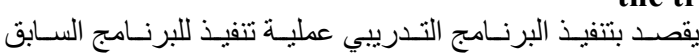
the training

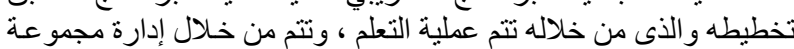

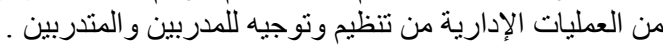

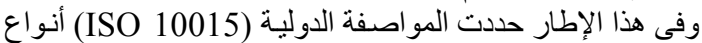

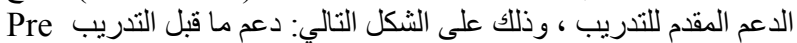
نهائ training support

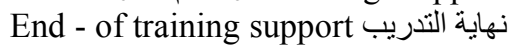

Evaluating training : المرحلة الرابعة : تقييم نتائج التدريب outcomes

يقصد بمرحلة تقييم التدريب بأنها عملية جمع المعلومات بهدف

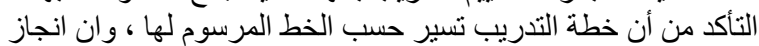

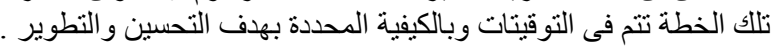


J. Agri. Econom. and Social Sci, Mansoura Univ., Vol.7 (3), March ,2016

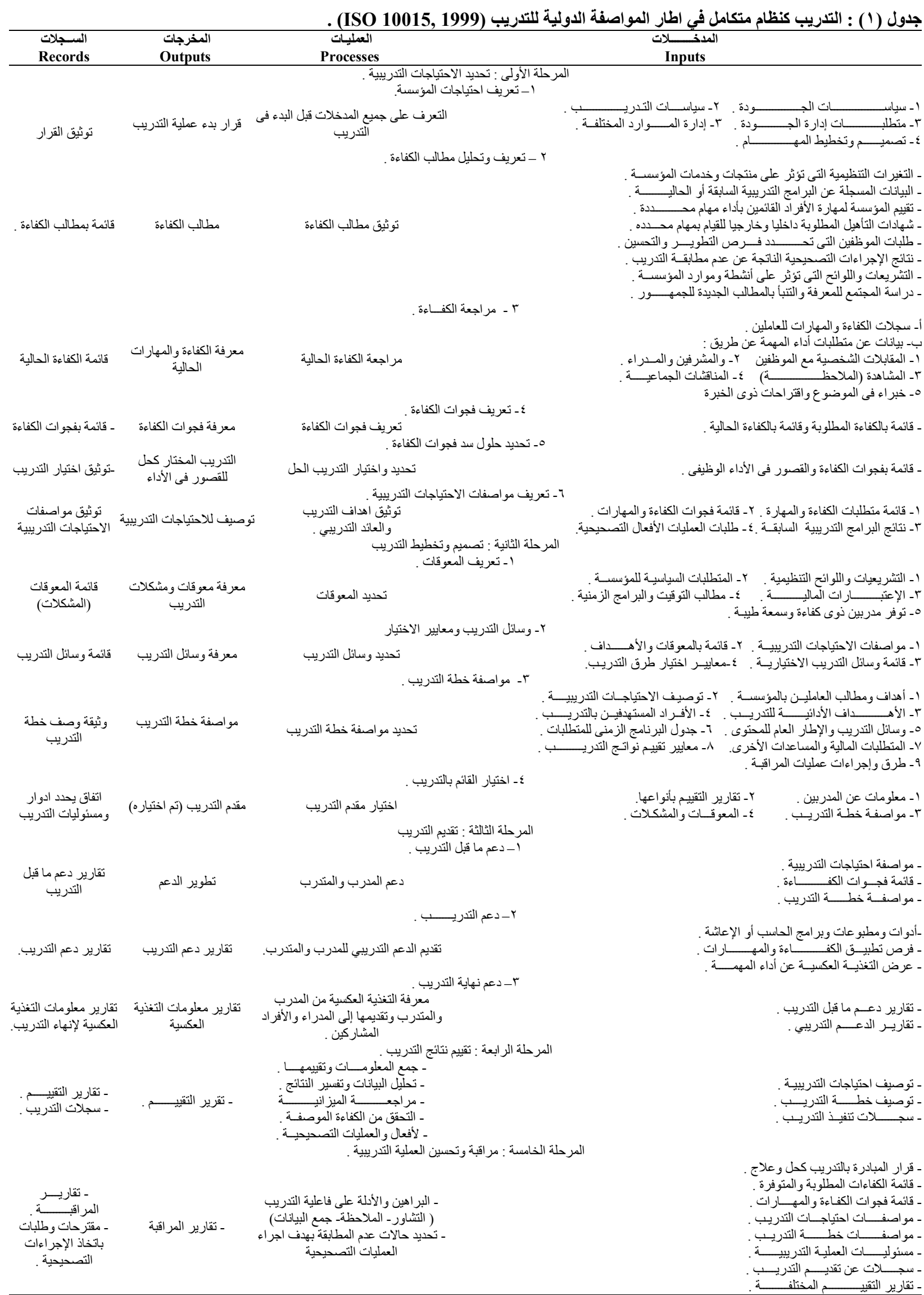




\section{Sarhan, A.M.M. and Rabab W. Ghozy}

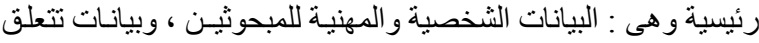

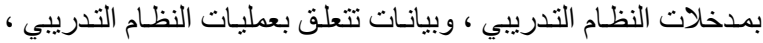

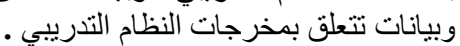

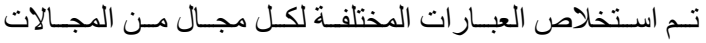

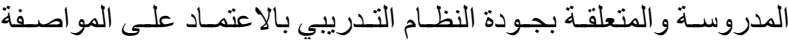

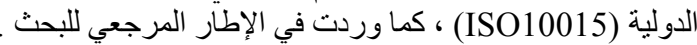

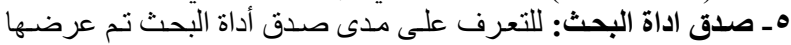

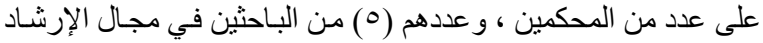

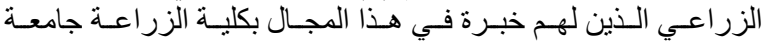

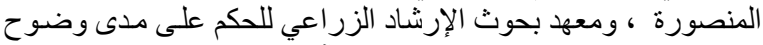

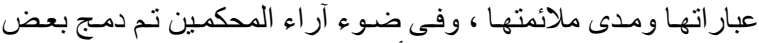

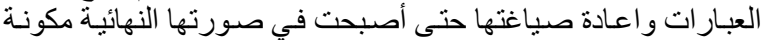

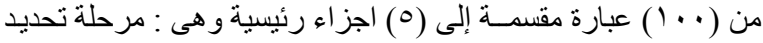

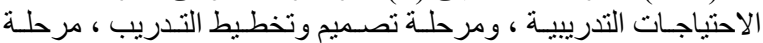

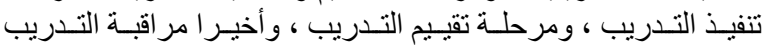
وتحسين فاعليته . 7ـ المعالجة الكمية للبيانات: تمت معالجة استجابهات المبات المبحوثين بما يلائم

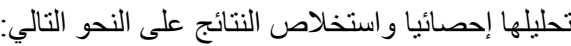

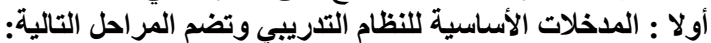

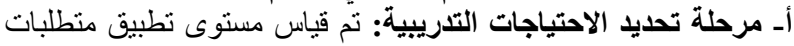

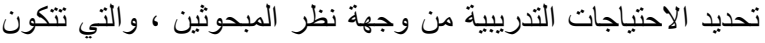

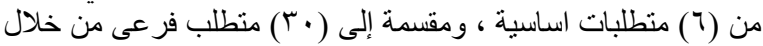

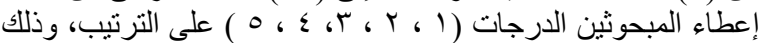

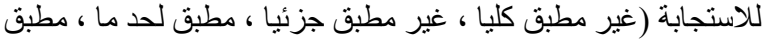

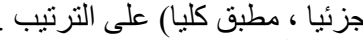
ب- مرحلة تصميم وتخطيط التدريب: علئ نم قياس مستوى تطبيق منطلبات

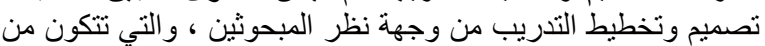

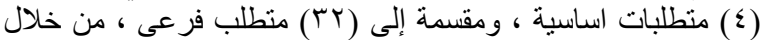

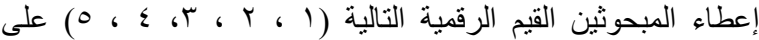

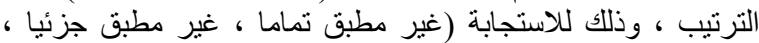

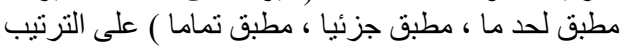

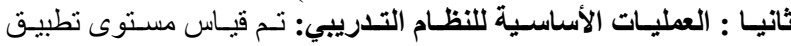

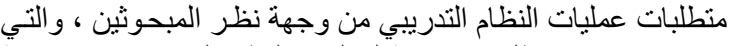

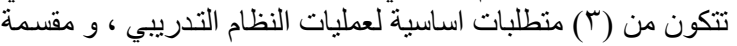

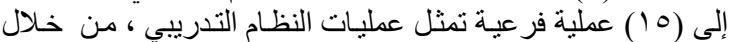

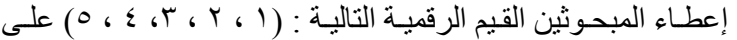

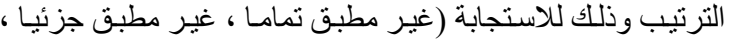

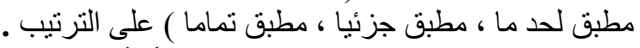

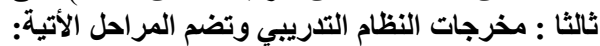

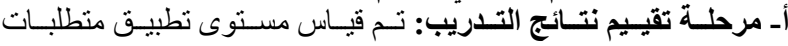

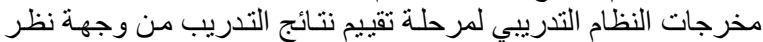

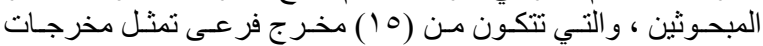

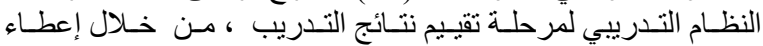

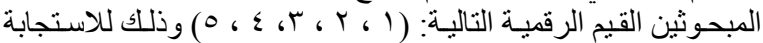

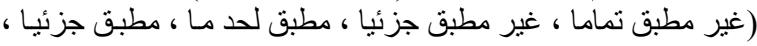

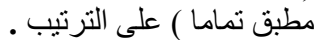
بـ مرحلة مراقبة وتحسبين العملية التدريبيةة: تم قياس مستوى تطبيق

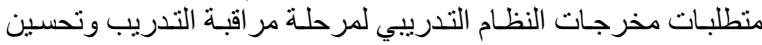

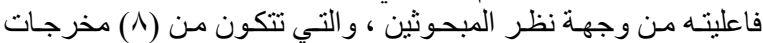

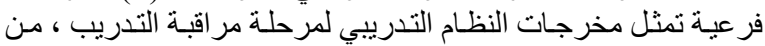

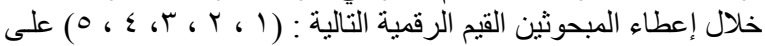

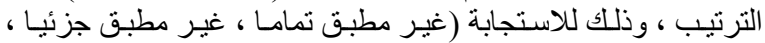

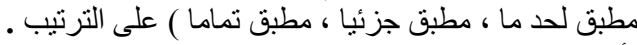

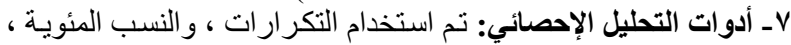

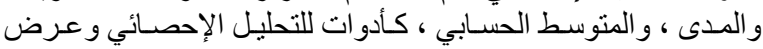

\section{النتائج ومناقشتها}

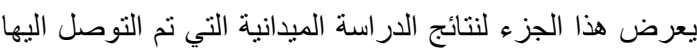

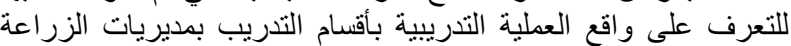

\section{الطريقة البحثية}

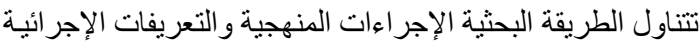

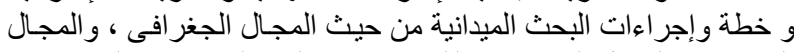

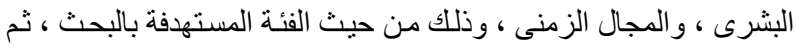

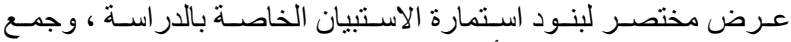

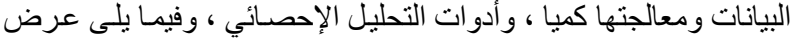

1اكتعريفــات الإجرائيـة : Operational Definitions الاراسة الحالية عدد من المفاهيم التي يمكن توضيحها فيما يلي :

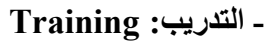

يقصد به في هذه الدر اسـة العملية الهادفة التي تعمل على تلى تزويد

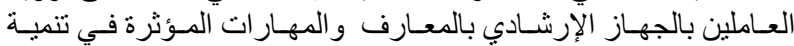

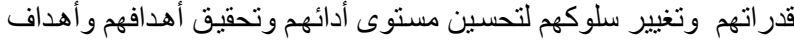

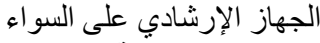

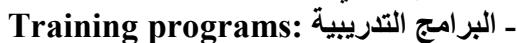

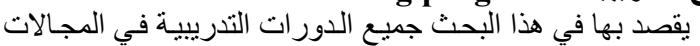

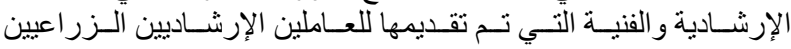

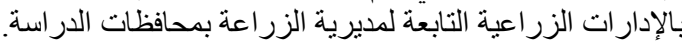

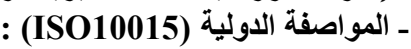

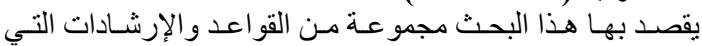

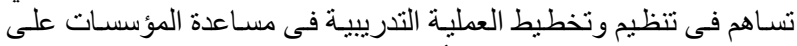

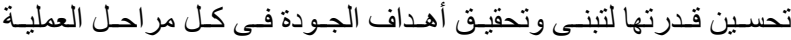

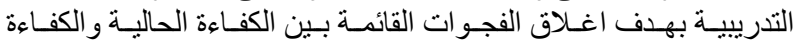

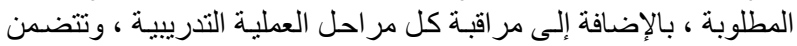

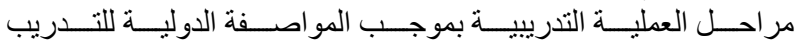

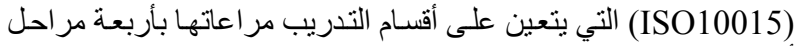
أساسية بالإضافة إلى مر اقبة العملية التدريبية ، و وهى : تحديد التحيد الاحتياجـات

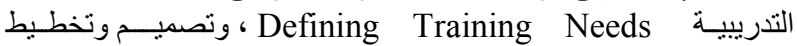

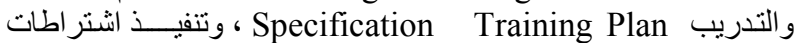
التدريب Providing for Training ، وتقييـــم مخرجــات التدريب :

Evaluating Training Outcomes ـ Inputs مدخلات النظام التدريبي

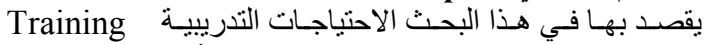
needs

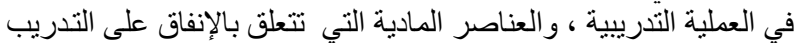

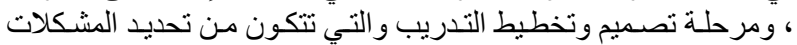

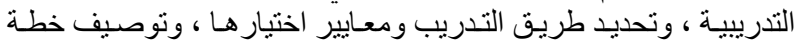
التدريب

ـ Pمليات النظام التدريبي Process التدريب

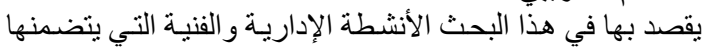

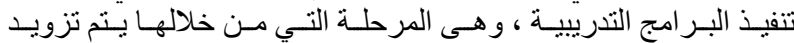

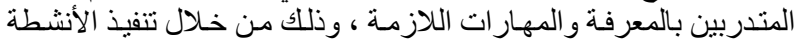

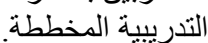

ـ مخرجات النظام التدريبي Outputs :

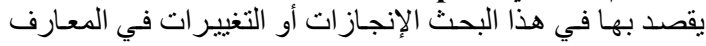

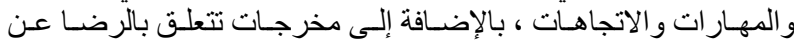

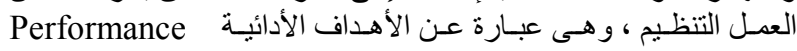
objectives

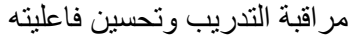

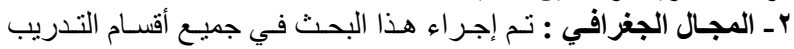

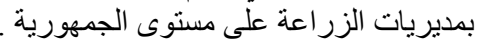
r- المجال البشرى : يتمثل المجال البشرى البرى للبحث في شاملة رؤساء أقسام

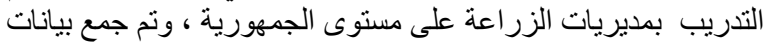

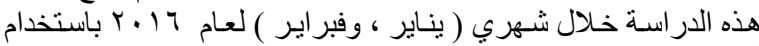

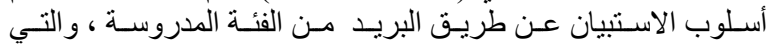

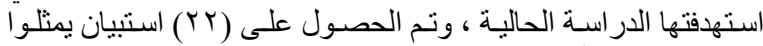

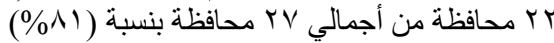

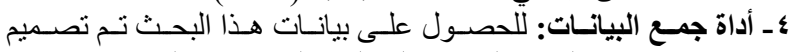

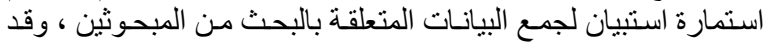

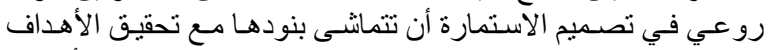

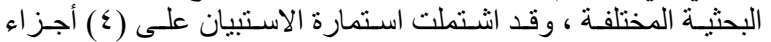




\section{J. Agri. Econom. and Social Sci., Mansoura Univ., Vol.7 (3), March ,2016}

أ-مرحلة تحديد الاحتياجات التذريبية :

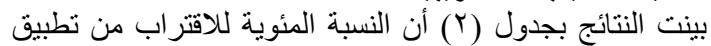

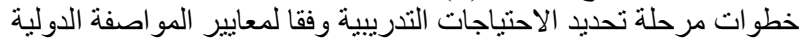

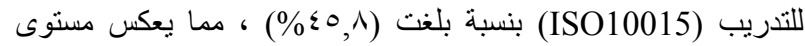

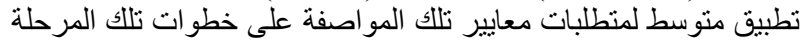

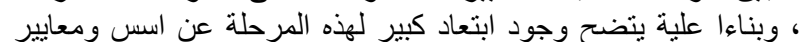

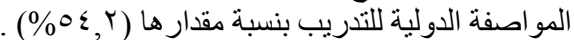

على مستوى الجمهورية ومقارنتها بأسس ومعايير المواصفة الدولية

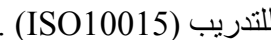
أولا : مدخلات النظام التشريبي : يعرض هذا الجزء أهم النتائج المتعلقة بمستوى تطبيق عناصر المواصفة الدولية للتدريب (ISO10015) و المرتبطة بمدخلات النئ النظام التدريبي من وجهة نظر المبحوثين للوقوف على مدى الاقتر اب أو الابتعاد

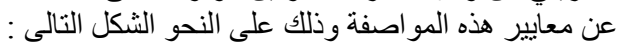

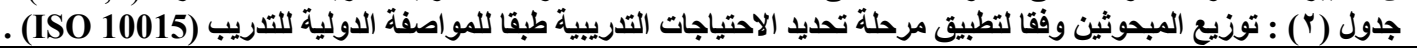

\begin{tabular}{|c|c|c|c|c|c|}
\hline $\begin{array}{l}\text { مطبق تماما } \\
(\%)(\cdots)\end{array}$ & $\begin{array}{c}\text { مطبق جزئيا } \\
(\% \text { V0) }\end{array}$ & 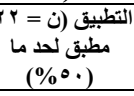 & غير مطبق جزئيا & غير مطبق تماما & أ أولا : ملة تحديد الاحتياجات التدريبي التدريبية \\
\hline - & 。 & 11 & $\varepsilon$ & r & 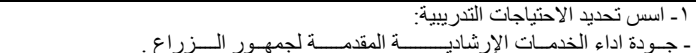 \\
\hline r & $\varepsilon$ & v & $\varepsilon$ & $\varepsilon$ & 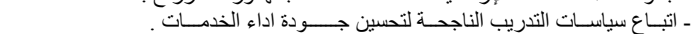 \\
\hline r & 。 & $\Lambda$ & 。 & $\varepsilon$ & 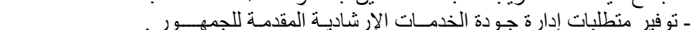 \\
\hline r & 。 & r & $\wedge$ & r & ـ إدارة مو ارد التندريب بكفاءة لضمان نجاح الدور ات و البر امج التنريبية. . \\
\hline 1 & 7 & $\begin{array}{l}\dot{0} \\
\%\urcorner \varepsilon, \varepsilon\end{array}$ & $v$ & r & 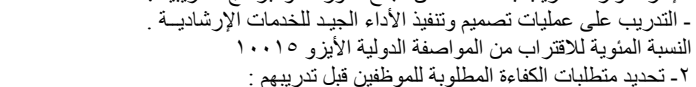 \\
\hline r & v & $\wedge$ & r & r & ـ مر اجعة الكفاءات والقدر ات الحالية للموظفين بالقسم و الإدارة الزر اعية . \\
\hline 1 & $\circ$ & $\wedge$ & r & ० & ـ التغير ات التنظيمية والتكنولوجية التي تؤثر في اداء الأنشطـة الإرشادية . \\
\hline 7 & r & 。 & v & 1 & ـ البيانات المسجلة عن الدورات التندريبية السابقة و الحالية للموظفيــن . \\
\hline r & $\mathrm{v}$ & 7 & r & r & 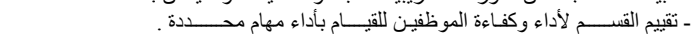 \\
\hline 1 & $v$ & 1. & r & r & ـاقترأحات الموظفين النتي تساهم في تطوير أهداف الجهـاز الإرشـــــي . \\
\hline- & $v$ & $\wedge$ & 7 & r & ـ ـنتائج مر اجعة الأداء وأَجر اءات ألتصحيح الناتجة عن شكاوى الـزراعً . \\
\hline r & $\varepsilon$ & $\circ$ & $\checkmark$ & $\circ$ & 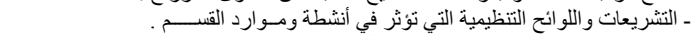 \\
\hline r & ○ & $\%$ & r & 7 & 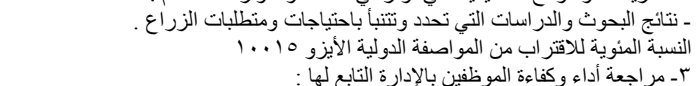 \\
\hline r & 7 & $\varepsilon$ & v & r & 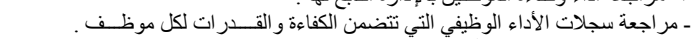 \\
\hline- & $\mathrm{v}$ & $\varepsilon$ & 。 & 7 & ـ جمع بيانات عن مستوى الاداء من خلال (مقابلات ـ ملاحظات - مناقثـــــات) . \\
\hline$\varepsilon$ & r & 7 & - & 7 & 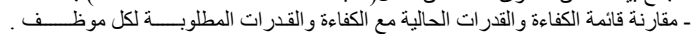 \\
\hline ) & r & 1 & 。 & v & 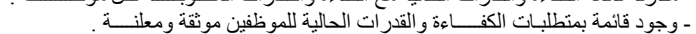 \\
\hline r & $\circ$ & $\begin{array}{l}1 \\
\%\end{array}$ & $\checkmark$ & 7 & 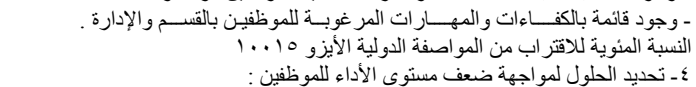 \\
\hline 。 & 1 & $\varepsilon$ & 。 & r & ـ عمل قائمة بالفجــوات بين مستــــوى الأداء الحالـــي و المر غوب للموظفيـن . \\
\hline r & $\wedge$ & ○ & $\varepsilon$ & r & 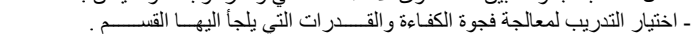 \\
\hline r & 7 & 1 & $\varepsilon$ & r & ـ مشاركة الموظفين مع الإدارة فى اختيار التدريب كحل وعلاج للقصور فى الأداء. \\
\hline- & r & 9 & $\checkmark$ & r & 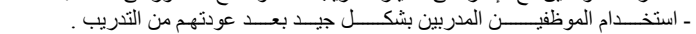 \\
\hline 1 & $\varepsilon$ & v & 7 & $\varepsilon$ & 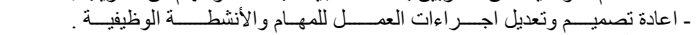 \\
\hline- & 7 & $\%$ $\%$ rv & $\circ$ & $\varepsilon$ & 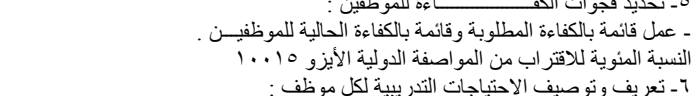 \\
\hline - & 1 & 9 & r & 。 & 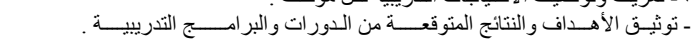 \\
\hline- & v & 7 & 。 & $\varepsilon$ & 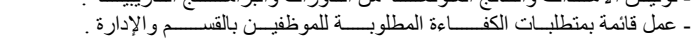 \\
\hline - & 。 & 1 & 。 & 7 & ـ ـ وجود قائمة بالقصور و الفجو ات فى قدرات ومهار ات ألموظفين موثقة ومعلنة . \\
\hline$\wedge$ & $\varepsilon$ & ० & $\varepsilon$ & 1 & 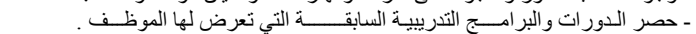 \\
\hline- & $\circ$ & $\varepsilon$ & 1. & r & 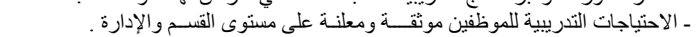 \\
\hline 1 & 1 & $\begin{array}{l}0 \\
\%\end{array} \leqslant \leqslant .0$ & $\varepsilon$ & 1 & 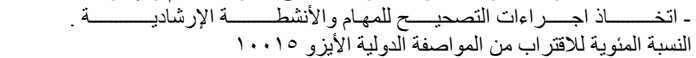 \\
\hline ov & $17 \varepsilon$ & 119 & 17. & $11 \mathrm{~V}$ & ـ ـ أجمالي التكرارات ل \\
\hline or.. & וr.. & $\begin{array}{l}9 \leq 0 . \\
\% \leq 0 . \wedge \\
\% \leq 0,1 \\
\% 0 \leq .4\end{array}$ & $\{\cdots$ & - & 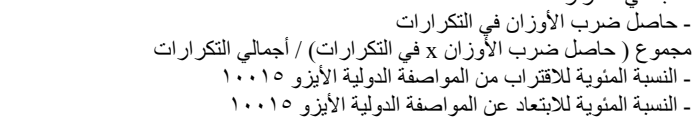 \\
\hline
\end{tabular}

مدى التقارب و الابتعاد من اسس ومعايير المو اصفة المدروسـة من وجهة

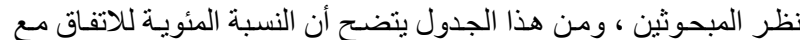

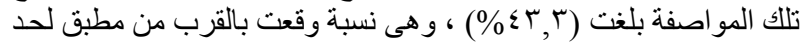

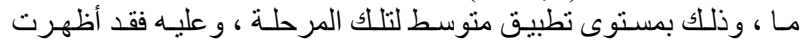

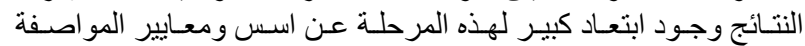

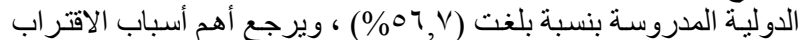

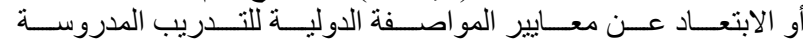

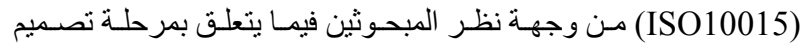
وتخطبط التدريب إلى : مدير

قبام مديرو أقسام التدريب بمديريات الزر اعة المدروسة باستخدام

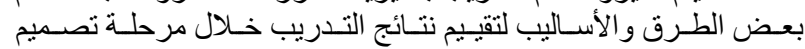

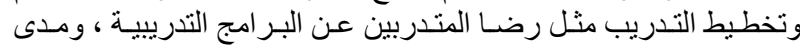

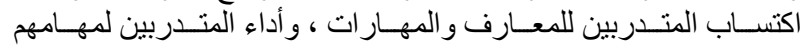

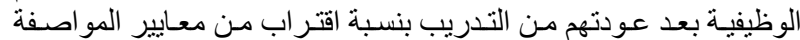

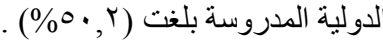

في حين أظهرت النتائج الواردة وجود قصور في تحديد منطلبات

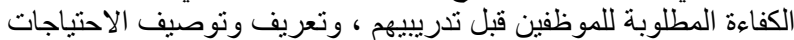

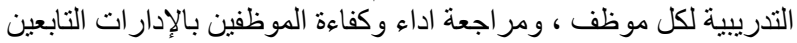

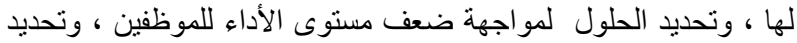

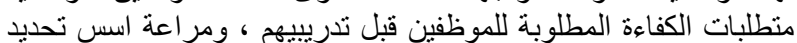

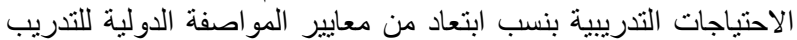

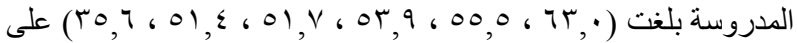

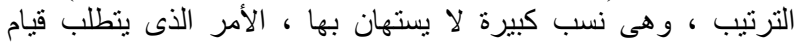

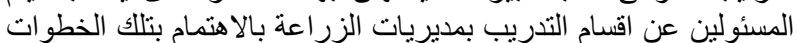

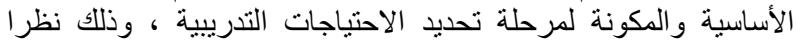

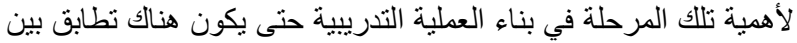

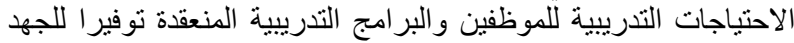

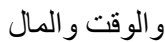
بـمرحلة تصميم وتخطيط التدريب :

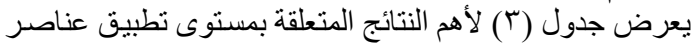

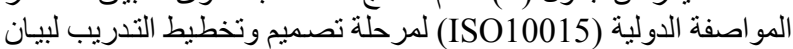


عناصر وخطوات مرحلة تصميم وتخطيط التدريب ، وخاصة الته اختيار

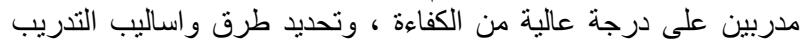

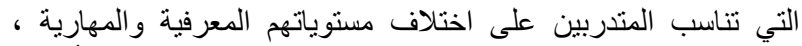

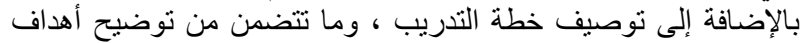

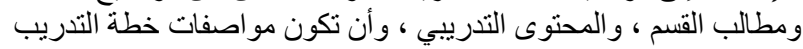

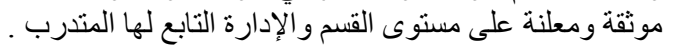

كما بينت النتائج وجود قصور في اختبار المدربين القائمين

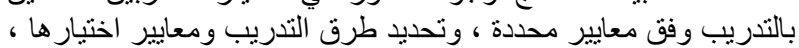

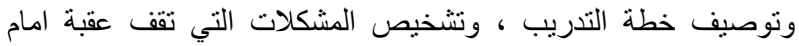

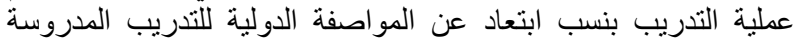

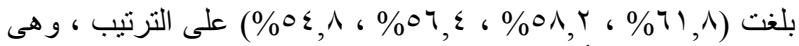

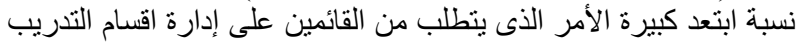

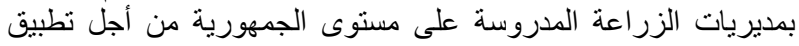

جدول (r) : توزيع المبحوثين وفقا لتطبيق مرحلة تصميم وتخطيط التدريب طبقا للمواصفة الدولية للتدريب (ISO 10015) .

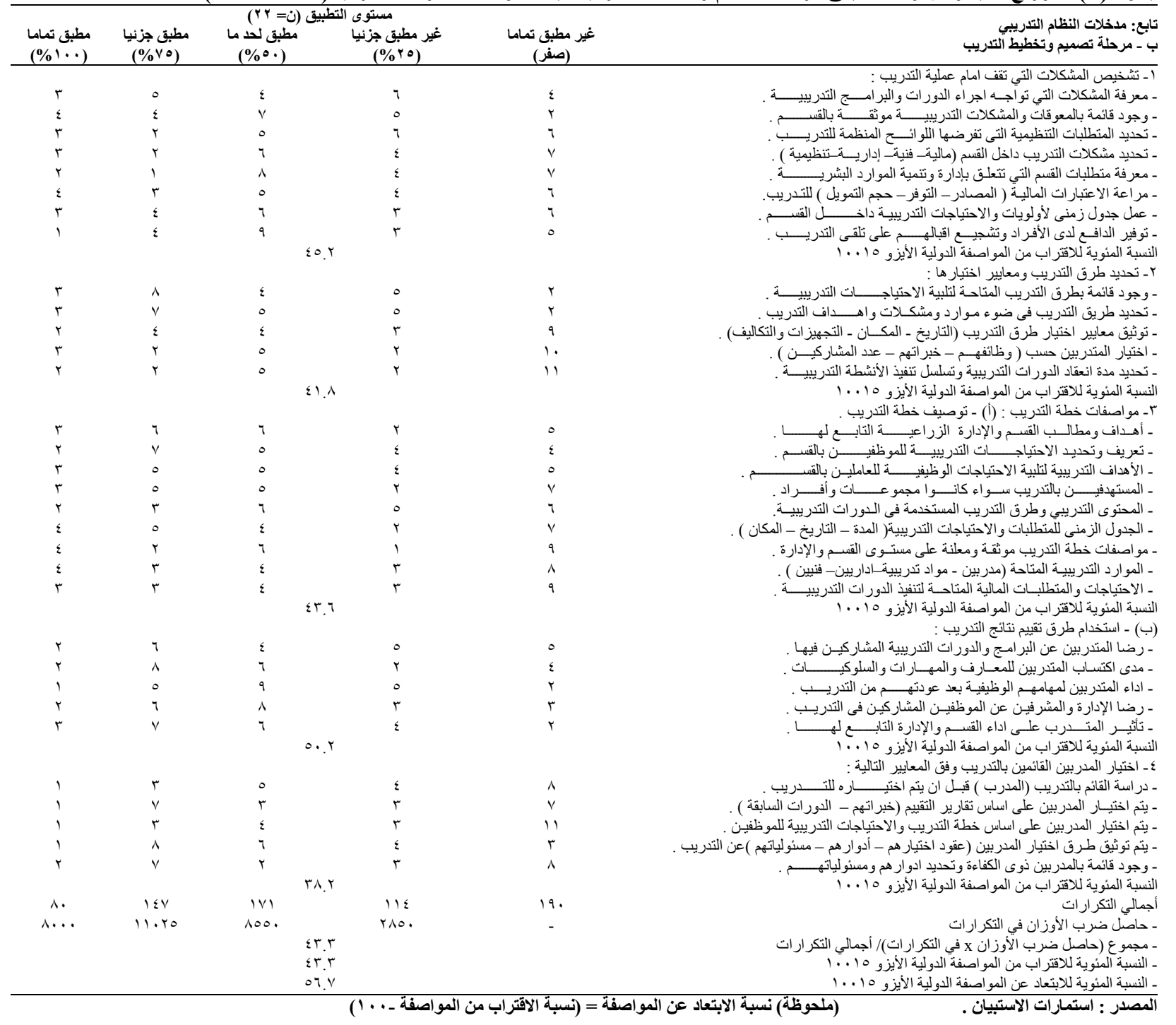

مقابل اختلاف وابتعاد عن معايير المواصفة الدولية للتدريب بنسبة بلغت وجود قصور في قيام أقسام التدريب بالأنشطة التالية أثناء تنفيذ

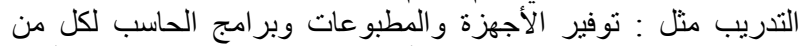

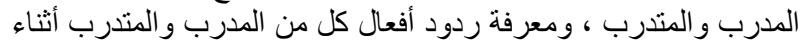

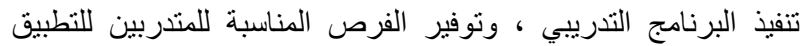

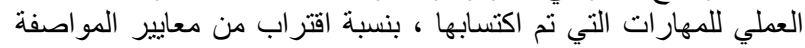

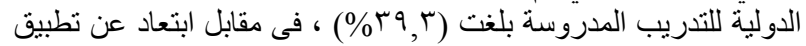

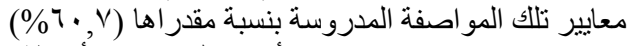

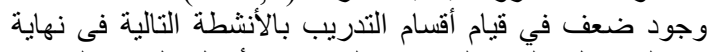

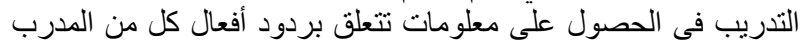

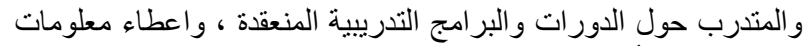

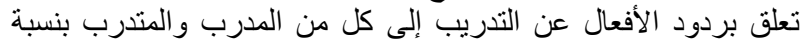

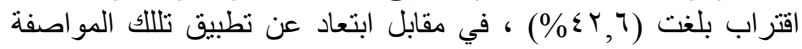

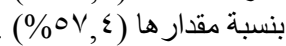

ثانيا : عمليات النظام التدريبي :

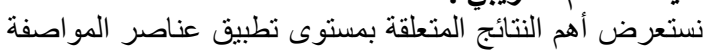

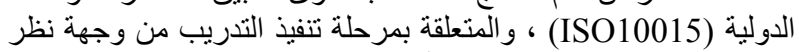

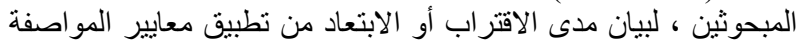

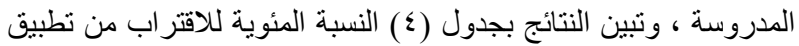

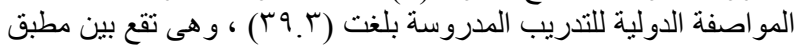

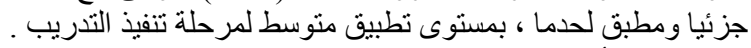

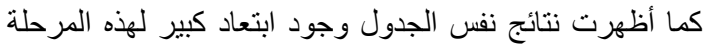

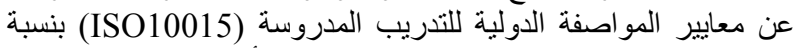

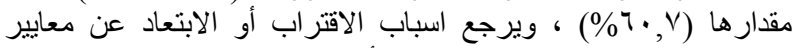

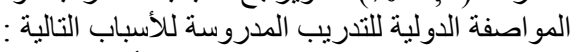
وجود قصور في قيام القسم بالأنشطة التالية قبل إجراء التهاء التدريب

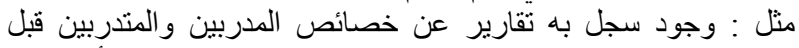

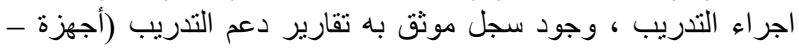

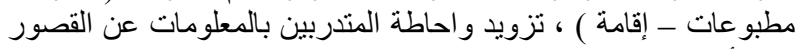

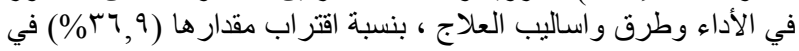


جدول (؛) : : توزيع المبحوثين وفقا لمستوى تطبيق مرحلة تنفيذ التدريب طبقا للمواصفة الدولية للتّريب (ISO 10015).

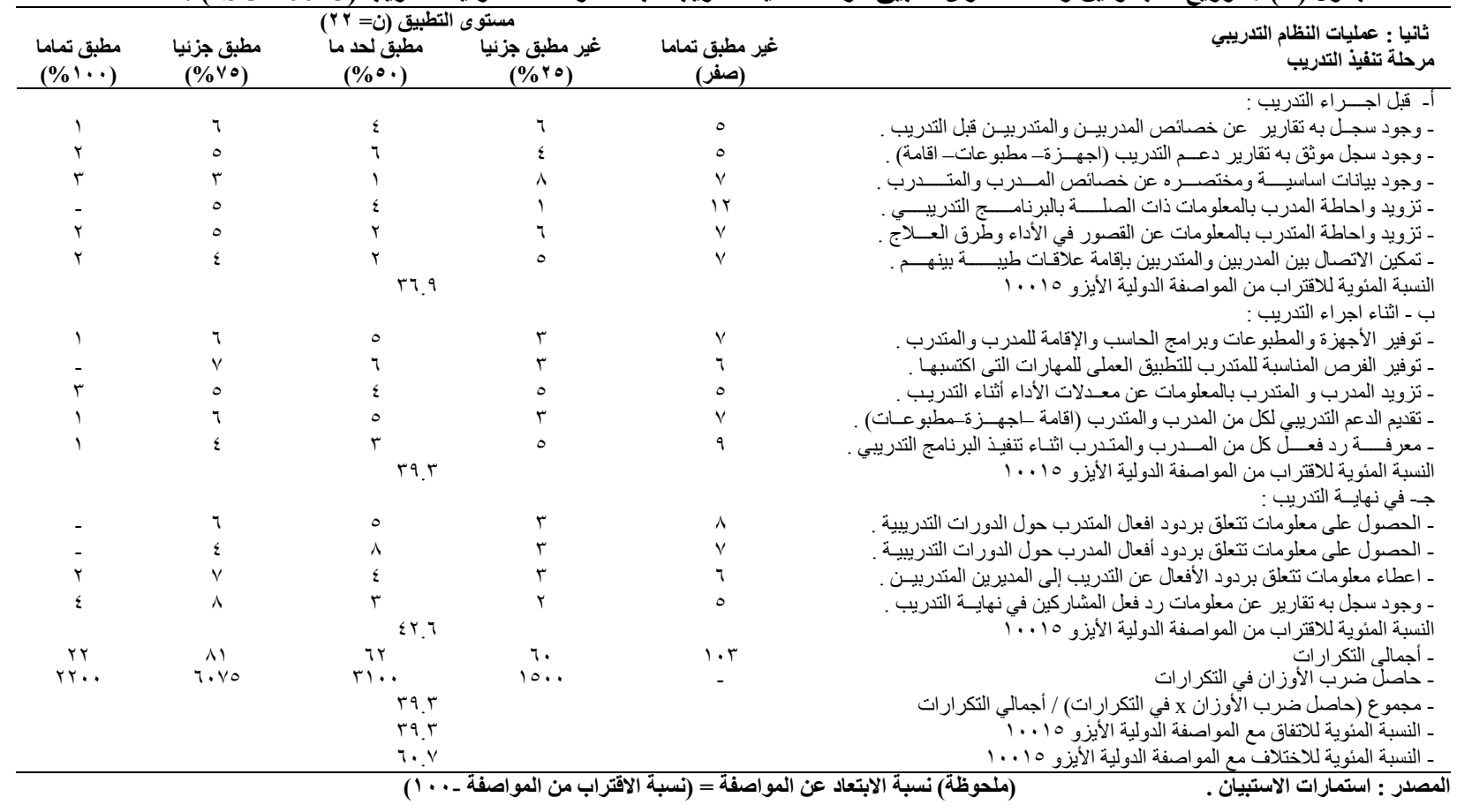

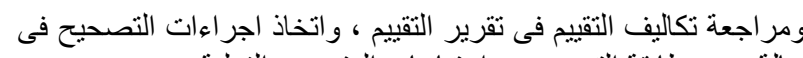

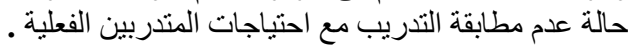

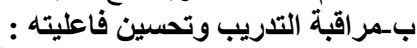

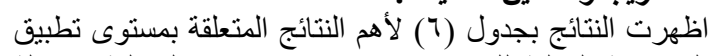

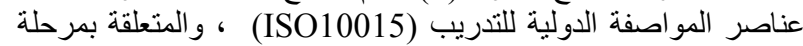

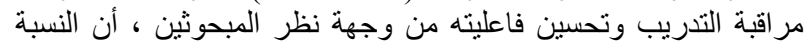

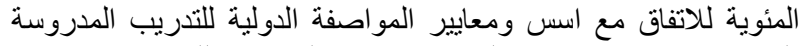

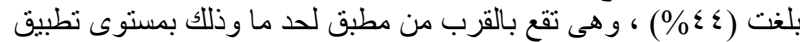

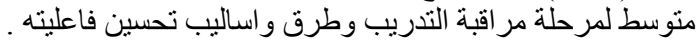

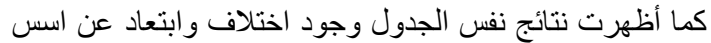

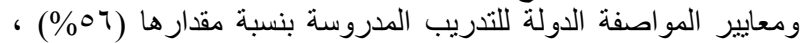

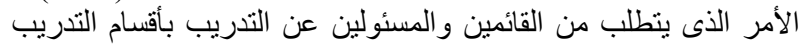

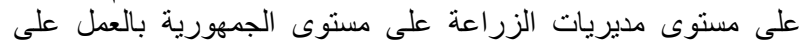

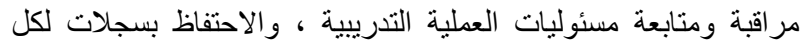
مرحلة من مراحل العملية التدريبية ، بالإضافة إلبة إلى مراقبة التفة مراحل التدريب المختلفة (خطة التدريب - التنفيذ - التقييم ) .

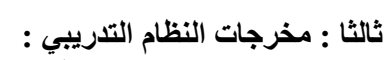

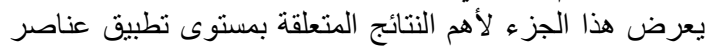

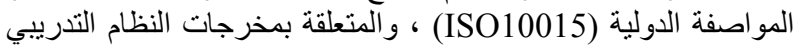

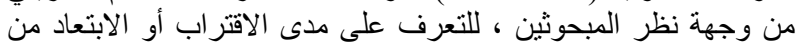

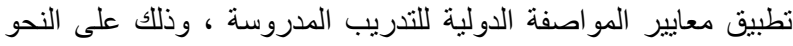
التالي : التبن : أـمرحلة تقييم نتائج التّريب :

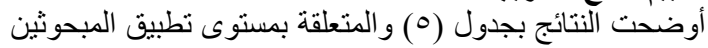

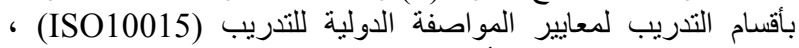

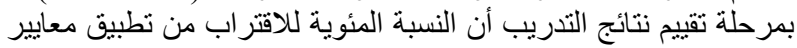

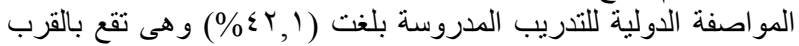

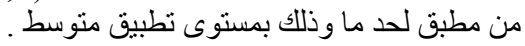

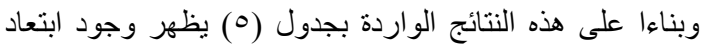

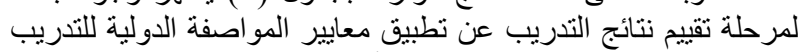

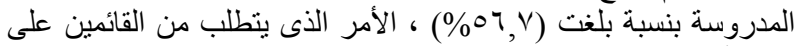

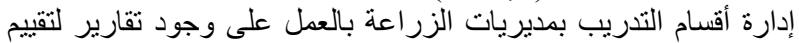

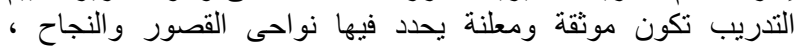

جدول (•) : توزيع المبحوثين وفقا لتقييم نتائج لتدريب طبقا للمو اصفة الدولية للتدريب (ISO 10015) .

\begin{tabular}{|c|c|c|c|c|}
\hline \multicolumn{5}{|c|}{ مستوى التطبيق (ن= Y Y } \\
\hline 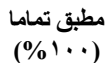 & $\begin{array}{c}\text { مطبق جزئيا } \\
\text { (\% \% ( ) }\end{array}$ & مطبق لحد ما (\%) & 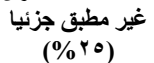 & غير مطبق تماما \\
\hline r & $\varepsilon$ & 7 & 1 & $r$ \\
\hline r & $\varepsilon$ & $\wedge$ & 0 & 1 \\
\hline 0 & 9 & $\varepsilon$ & $\varepsilon$ & - \\
\hline$r$ & 7 & r & $\varepsilon$ & 1 \\
\hline$r$ & $r$ & $\varepsilon$ & $r$ & 9 \\
\hline$r$ & $\varepsilon$ & 0 & 0 & 0 \\
\hline 1 & V & $\varepsilon$ & $r$ & V \\
\hline r & 1 & 7 & 7 & V \\
\hline$r$ & $\varepsilon$ & 0 & $\varepsilon$ & 7 \\
\hline 1 & 7 & 7 & 0 & $\varepsilon$ \\
\hline 1 & 7 & V & $r$ & V \\
\hline - & 0 & 7 & $r$ & $\wedge$ \\
\hline - & $r$ & V & 0 & $\wedge$ \\
\hline r & $r$ & $\varepsilon$ & $r$ & 1. \\
\hline$r$ & 7 & $r$ & $r$ & V \\
\hline r & $v$. & $\mathrm{VA}$ & $T \leqslant$ & AV \\
\hline r... & oro. & rq.. & $17 \ldots$ & - \\
\hline
\end{tabular}

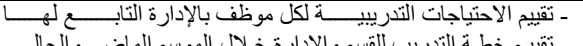

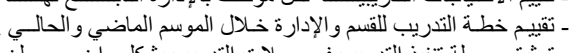

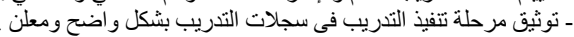

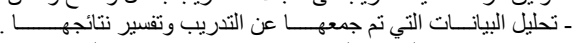

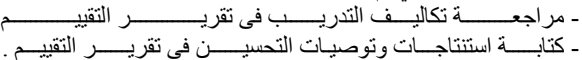

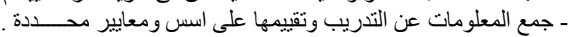

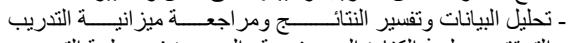

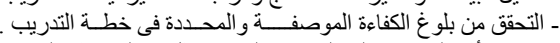

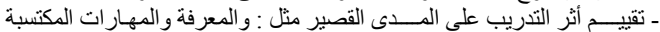

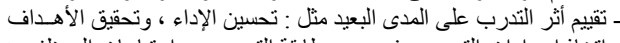

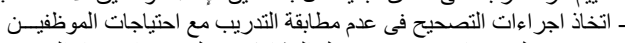

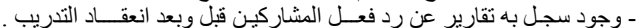

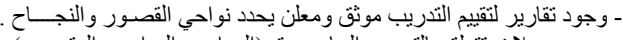

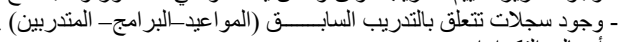

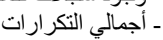

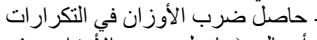

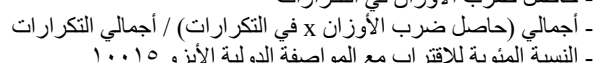

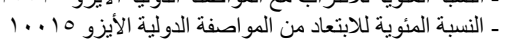


تابع جدول (7) : توزيع المبحوثين وفقا لمراقبة التدريب وتحسين فاعليته طبقا للمواصفة الدولية للتدريب (ISO 10015) .

\begin{tabular}{|c|c|c|c|c|c|}
\hline \multirow[b]{2}{*}{ مطبق تماما } & \multicolumn{3}{|c|}{ مستوى التطبيق (ن= Y Y TY) } & \multirow[b]{2}{*}{ غير مطبق تماما } & \multirow{2}{*}{ 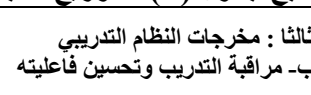 } \\
\hline & $\begin{array}{c}\text { مطبق جزئيا } \\
\text { (\% \% ) }\end{array}$ & مطبق لدا ما & 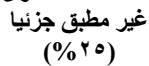 & & \\
\hline
\end{tabular}

\begin{tabular}{|c|c|c|c|c|}
\hline 1 & 0 & $\varepsilon$ & $\varepsilon$ & $\wedge$ \\
\hline$r$ & $\varepsilon$ & $\varepsilon$ & $r$ & 9 \\
\hline$\varepsilon$ & $r$ & 0 & $r$ & $\wedge$ \\
\hline 0 & 0 & $\varepsilon$ & 0 & $r$ \\
\hline$\varepsilon$ & $\varepsilon$ & V & $r$ & $\varepsilon$ \\
\hline 0 & $r$ & 0 & $\varepsilon$ & 0 \\
\hline$r$ & $\varepsilon$ & 7 & $r$ & 1 \\
\hline$\varepsilon$ & $r$ & 0 & $r$ & $v$ \\
\hline rA & r. & $\varepsilon$. & rA & 0. \\
\hline r৯.. & rro. & $r \ldots$ & v.. & - \\
\hline \multicolumn{5}{|c|}{$\varepsilon \varepsilon}$. \\
\hline \multicolumn{4}{|c|}{$\varepsilon \varepsilon}$, & \\
\hline
\end{tabular}

07 .

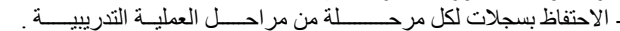

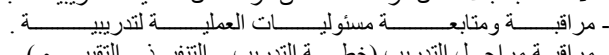

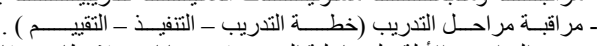

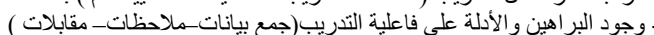

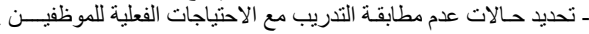

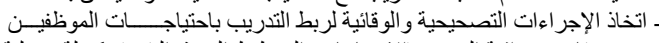

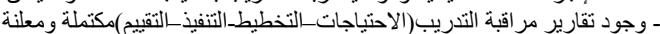

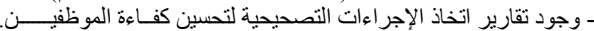

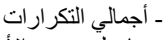

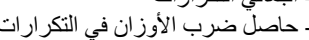

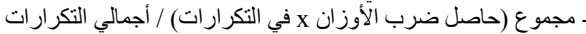

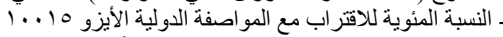

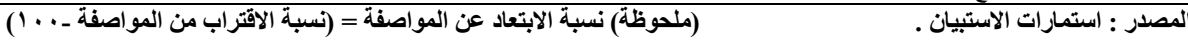

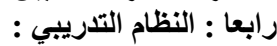

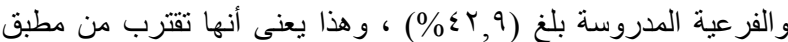

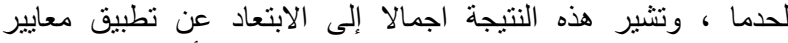

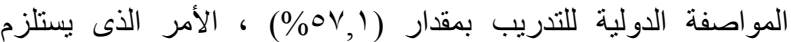

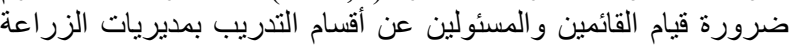

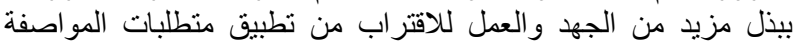

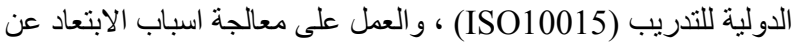

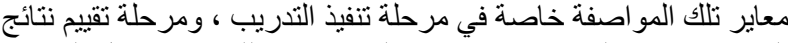

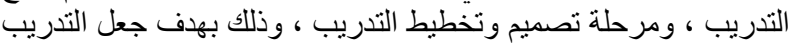

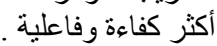

تعرض أهم النتائج التي تم التوصل إليها لتبين و اقع العملية

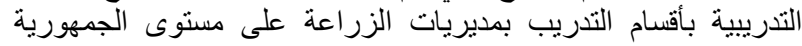

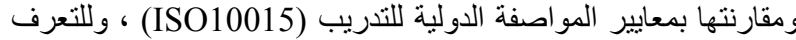
على مدى الاقتر اب و الابتعاد من تطبيق معايير تللك المو اصفة المدربة المدروسة ،

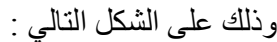

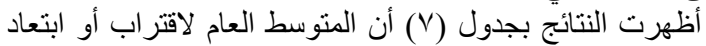

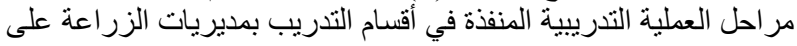

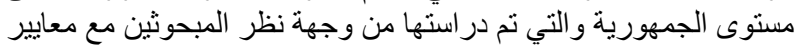
المواصفة الدولية للتدريب (ISO10015) بجميع منطلبناتها الرئيسية

جدول (V) : المتوسط العام لاقتراب وابتعاد مراحل العملية التدريبية عن المواصفة الدولية للتدريب (ISO10015) ـ (ISU) .

\begin{tabular}{|c|c|}
\hline $\begin{array}{l}\text { عن التمواصفة الاولية } \\
\text { (ISO10015) }\end{array}$ & مع المواصفة الدولية (ISO10015) \\
\hline 1 & $r \cdot, V$ \\
\hline r & ov, 9 \\
\hline$r$ & $07, \mathrm{~V}$ \\
\hline$\varepsilon$ & 07, \\
\hline 。 & $0 \leqslant, Y$ \\
\hline & ov,, \\
\hline
\end{tabular}

تشير نتائج هذا البحث إلى ضرورة فئلى فيام المسئولين عن إدارة

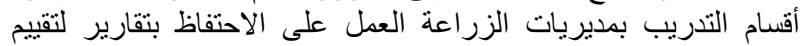

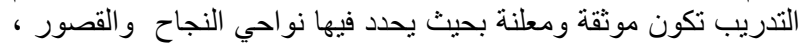

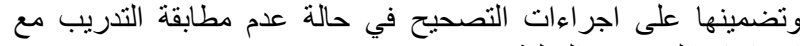

احتياجات المتدربين الفعلية .

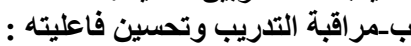

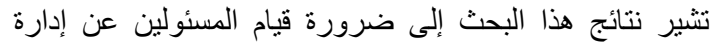

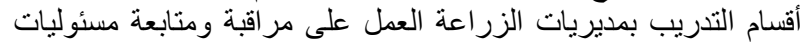

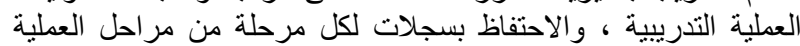

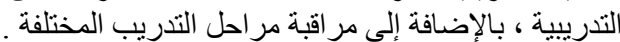

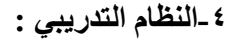

كثفت نتائج البحث التي تم التوصل إلتئ إليها عن أن المتوسط العام

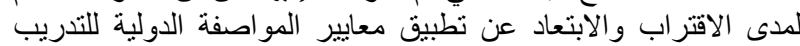

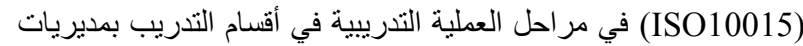

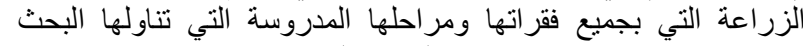

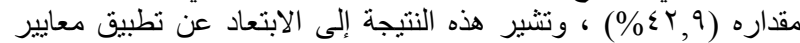

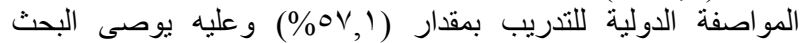

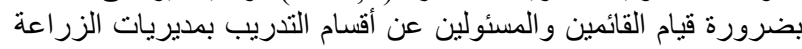

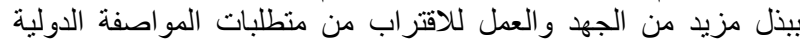

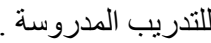

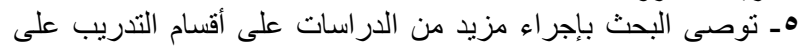

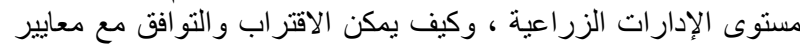

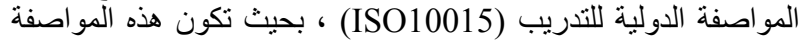
بمثابة أهداف قريبة ومنوسطة الأجل يجب على المسئولين عن أقسام

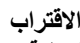

مع المواصفة الدولية (15) - مئراب

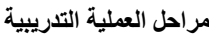

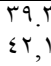

$\varepsilon r, r$

$\varepsilon \varepsilon$.

$\leqslant 0, \wedge$

$\leqslant r, 9$

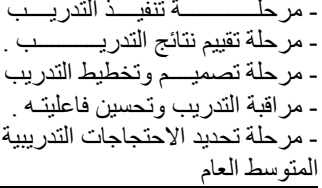

في ضوء مأ توصل الرئيه والثوصيات البحث من نتائج أمكن بلورة عددا من

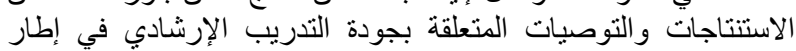

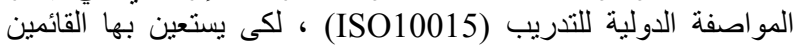

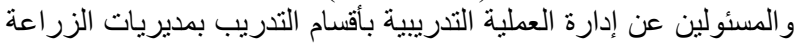

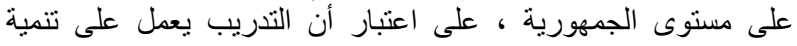

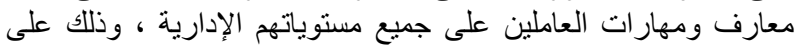

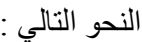

إـمدخلات النظام التدريبي :

أمرحلة تحديد الاحتياجات التدريبية :

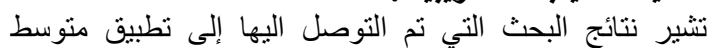

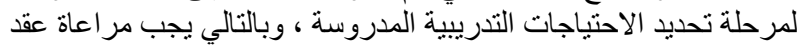

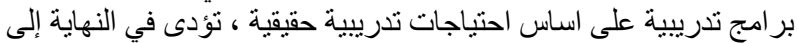
استثمار في الوقت و الجهد و المال . ب-مرحلة تصميم وتخطيط التدريب :

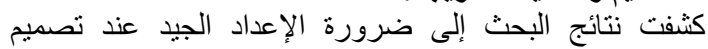

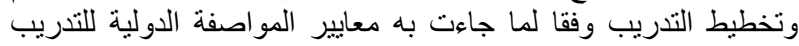

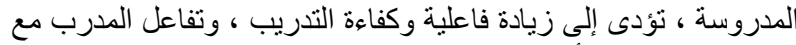

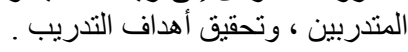

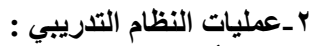

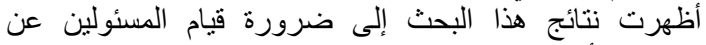

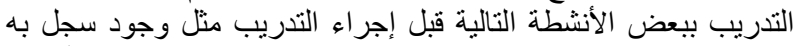

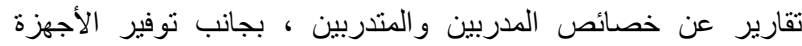

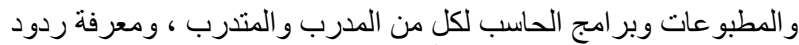

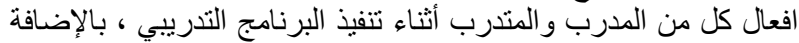

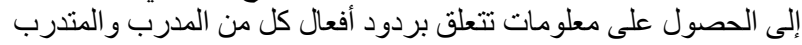

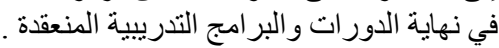


FAO, (2004): ICT Needs for Improved Agricultural in Croatia . http://fao.org/sd

Gould-Williams, J. (2003): The importance of human resource practices and workplace trust in achieving superior performance: A study of public-sector organizations. International Journal of Human Resource Management, 14:1 February.

International Standard Organization ISO 10015. (1999). Quality Management - Guidelines for Training, printed in Switzerland, [online] http://www.iso.ch

Jacobs, R.L. and Wang, B. (2007): A Proposed Interpretation of the ISO 10015and Implications for HRD theory and Research, the Ohio State University, USA.

Kandi, M. (2011): The Role of Training, Documentation of Experience and Management Counseling in Management of Vocational Schools in Tehran. Journal of American Science, Vol.7, No.11 [online] http://www.americanscience.org

Noe, R.M., Hollenbeck, J.R., Gerhart, T.B., and Wright, P.M. (1995):Human Resource Management A Competitive Advantage, Austen press, Richard, D. IRWIN, Inc, U.S.A.

Rusell, R.S. and Taylor, B.w. (1995): Production and Operation Management: Focusing on quality and competencies, $1^{\text {st }}$ ed, 279Prentice Hall, Inc., New, Jersey, U.S.A.

Sanderson, G., ( 1992) : Objective and Evaluation, Hand Book of Training Development, Oxford edited by Steve Truelove.

Saner, R. and Yiu, L. (2013). " Does it pay to train? ISO 10015 assures the quality and return on investment of training" ISO Management System, March-April, pp. 9-13.

Vijayaragavan, k., Singh, P., \& Wasen, M. (2005) : Developing Training Modules for Improving Management Skills of Extension Professionals, Association of International Agricultural Extension and Education (AIAEE),Proceeding of the $21^{\text {st }}$ Annual Conference, San Antonio, TX.

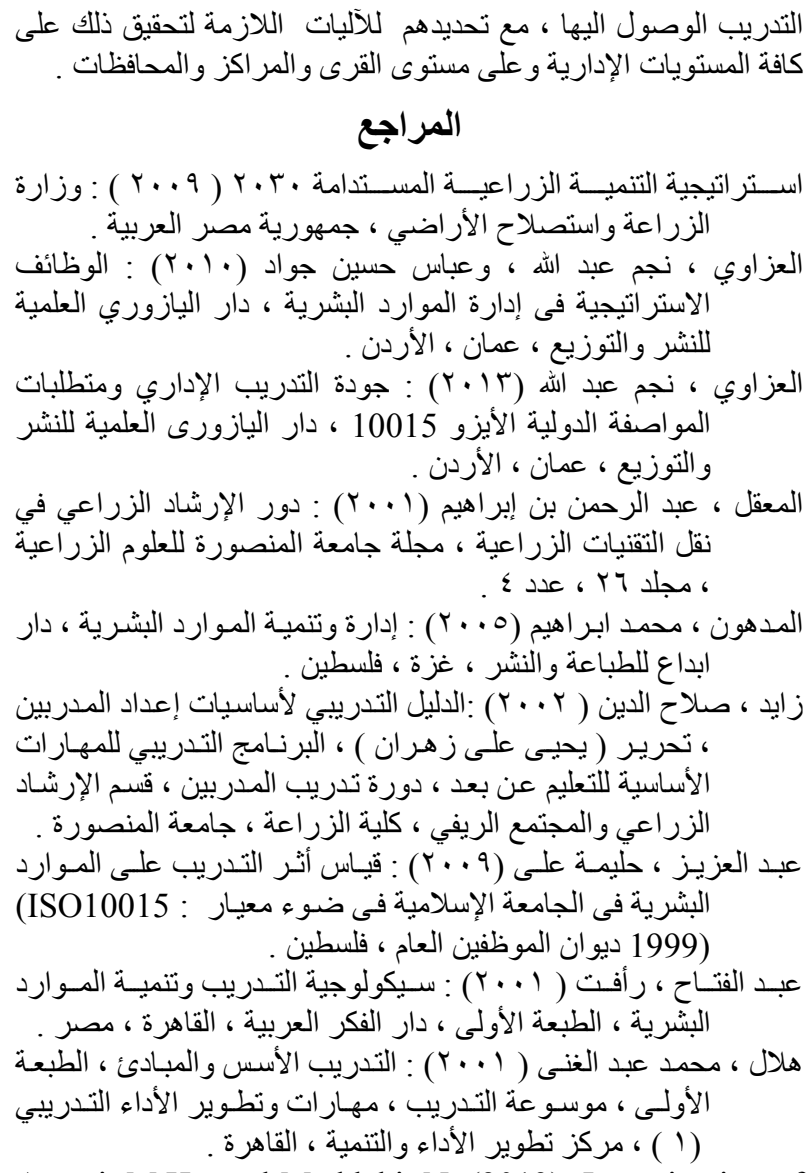

Asgari, M.H., and Maddahi, N. (2013): Investigation of Relationship between Establishment of Quality Management System and Customers Satisfaction in Saman Insurance Company, Technical Journal of Engineering and Applied Science, Vol.3, No.20. [ online] www.tjeas.com

Christian, J.R \& Reyntjens, D. (1998): Notes on Training Needs Assessment. www.fao.http://copemedorgrepotrstnameethodpr. htm

\title{
QUALITY OF EXTENSION TRAINING IN EGYPT BASED ON INTERNATIONAL STANDARD ISO 10015: CASE STUDY OF THE TRAINING DEPARTMENTS DIRECTORATES AGRICULTURE ON THE REPUBLIC.
}

Sarhan, A.M.M. and Rabab W. Ghozy

Agricultural Economic and Extension Dept., Faculty of Agric., South Valley University

Agricultural extension and rural dept., Faculty of Agriculture, Mansoura University

\begin{abstract}
The current study aimed mainly to identify the application of international standard training (ISO10015) in the training departments directorates of agriculture at the level of the Republic, in order to determine the quality of training in Egypt based on the international standard for training (ISO10015), The population of the study heads of training departments.

The respondents surveyed were data collection of this study during the month (January and February) 2016. The instrument used to achieve objectives of the study was a questionnaire method by mail, and used frequencies, and percentages, and the arithmetic mean, were used for data presentation and analysis.

The main finding for the study were :

1-The respondents indicated a moderate level $(44,5 \%)$ the general average inputs of training system.

2-The respondents indicated a moderate level $(39,3 \%)$ the general average process of training system.

3 -The respondents indicated a moderate level $(43,1 \%)$ the general average of training system.

4-the general average of training system agreement with international standard (ISO10015) a low level $(42,9 \%)$.

5 -the general average of training system difference with international standard (ISO10015) a moderate level $(57,1)$.
\end{abstract}

